\title{
Aproximación epistemológica a la traducción y la accesibilidad en el contexto digital: propuesta de una taxonomía
}

\section{Epistemological approach to translation and accessibility in the digital context: a taxonomy proposal}

\author{
María Asunción Arrufat Pérez de Zafra \\ Universidad de Granada \\ arrufat@ugr.es \\ Orcid: https://orcid.org/0000-0002-2153-1201
}

\author{
Cristina Álvarez de Morales Mercado \\ Universidad de Granada \\ cristinaalvarez@ugr.es \\ Orcid: https://orcid.org/0000-0002-8298-8686
}

\section{ntroducción}

Hoy en día la relación que tienen los usuarios con los contenidos audiovisuales y las nuevas tecnologías ha sufrido un gran cambio. Hasta hace una década se hacía prácticamente un uso de la tecnología exclusivamente con fines laborales, sin embrago, se ha pasado en la actualidad a una sociedad en la que prima el uso intensivo de los medios digitales en cualquier ámbito de la vida social, lo que ha favorecido el desarrollo de un nuevo escenario comunicativo en el que el diseño universal se constituye como un elemento necesario para evitar la infoexclusión o la discriminación directa de usuarios (Hassan Montero y Martín Fernández 2004; Varela 2015). En el inicio de la conceptualización de la supresión de barreras, existía una clara connotación al establecer los tipos de población: aquella que es normal, es decir, la que se ajusta a lo que socialmente está establecido como «normativo» y aquella que estaría apartada de la normalidad a causa de sus discapacidades (Iwarsson y Stahl 2002). No obstante, este concepto ha evolucionado y se ha puesto de manifiesto la diversidad de la población y la necesidad de diseñar los entornos, productos y servicios con el fin de que sean accesibles para el mayor número de personas posible (Mace et al., 1990). De esta manera, es necesario adoptar un modelo de intervención integral que tenga en cuenta la supresión de barreras y el diseño para todos (Sala y Alonso 2005: 47). El modelo propuesto por Sala y Alonso tiene un carácter más genérico centrado en las barreras y las medidas que se pueden interponer. Sin embargo, en el entorno digital, la usabilidad ha sido la responsable de mejorar la experiencia del usuario en el uso de la tecnología, siendo definida por Nielsen (1993) como «la cualidad de un sistema por la que resulta fácil de aprender, fácil de utilizar, fácil de recordar, tolerante a errores y subjetivamente placentero». Unos principios que recuerdan a algunos de los aspectos esenciales del diseño universal: simple e intuitivo, tolerante al error y uso equiparable, lo que implica que el diseño sea atractivo para todos los usuarios. Ante una población diversa, la usabilidad permite mejorar la facilidad con la que el usuario navega e interactúa con la información y, en este contexto, las modalidades de Traducción e Interpretación Accesible (TeIA) tienen un papel fundamental. Han sido amplio objeto de investigación desde los estudios de Traducción Audiovisual (Díaz Cintas 2007a; Orero 


\section{Resumen:}

Las modalidades de Traducción e Interpretación Accesible (TelA) han sido amplio objeto de investigación desde los estudios de Traducción Audiovisual (Díaz Cintas 2007a; Orero 2007; Álvarez de Morales et al., 2012). Sin embargo, su delimitación en el contexto digital se encuentra en un estado aún propedéutico (Greco 2019: 19). En el siguiente artículo realizamos una reflexión sobre la revisión bibliográfica (Jiménez Hurtado 2007; Tercedor et al., 2007a; Báez Montero 2010; Martínez 2015; Cabezas Gay 2017; Medina Reguera 2018) para delimitar su ubicación epistemológica dentro del contexto específico de estudio, definiendo las particularidades que distinguen a las modalidades de TelA y aportando finalmente una propuesta de taxonomía específica que incluye la descripción verbal, la interpretación a códigos visuales gestuales, la transcripción y la adaptación textual. Su análisis y estudio como elementos del Diseño Universal es clave para profundizar en la implementación de soluciones de accesibilidad efectivas para los todos los usuarios.

Palabras clave: traducción, accesibilidad digital, diseño universal, modalidades de traducción accesible, traductología

\begin{abstract}
:
Accessible Translation and Interpreting Modalities have been extensively researched by the Audiovisual Translation Studies (Díaz Cintas 2007a; Orero 2007; Álvarez de Morales et al., 2012). However, its delimitation in the digital context is still in a propaedeutic stage (Greco 2019: 19). In the following article, we study the bibliographic review (Jiménez Hurtado 2007; Tercedor et al., 2007a; Báez Montero 2010; Martínez 2015; Cabezas Gay 2017; Medina Reguera 2018) according to the last Audiovisual Modalities in Translation and Interpreting in order to delimit its epistemological location within the specific context of study, in one hand, we will define the particularities that distinguish them and, on the other hand, we will provide a proposal for a specific taxonomy that includes the verbal description, the interpretation of visual-gestural codes and the transcription and the text adaption. Its analysis and further research, considered as elements of Universal Design, is key to deepen the implementation of effective accessibility solutions for all users.
\end{abstract}

Keywords: Translation, eAccessibility, Universal Design, Accessible Translation and Interpreting Modalities, traductology

2007; Jiménez Hurtado 2007; Álvarez de Morales et al., 2012). Sin embargo, su delimitación en el contexto digital se encuentra en un estado aún propedéutico (Greco 2019: 19). El contexto digital o virtual está determinado por los entornos que generan las tecnologías de la información y de la comunicación (Lapeyre 2018), definiendo entorno como un conjunto de espacios y objetos donde se realizan interacciones y procesos que, en el caso de las TIC, presenta interfaces habilitadas o soportadas por procesadores y conexiones electrónicas. Según Greco (2019), los estudios de Accesibilidad engloban un gran número de disciplinas y la evolución secuencial ha pasado de las perspectivas particularistas hacia una perspectiva universalista. Esta perspectiva entiende que los estudios de Accesibilidad a los Medios de Comunicación - Media Accessibility (MA) definidos por Szarkowska et al. (2013) y citado por Greco (2016:11) como:

El área de investigación que aborda las teorías, prácticas, tecnologías e instrumentos que facilitan el acceso a los productos, servicios y entornos de los medios de comunicación a personas que no pueden acceder, o no pueden adecuadamente, al contenido en su forma original (Greco 2016: 11).

Comparten parte de su área de conocimiento con los estudios de Traducción Audiovisual -Audiovisual Translation (AVT)- definidos por Chaume (2004: 30) como:

Una variedad de traducción que se caracteriza por la particularidad de los textos objeto de la transferencia interlingüística. Estos objetos, como su nombre indica, aportan información (traducible) a través de dos canales de comunicación que transmiten significados codificados de manera simultánea: el canal acústico (las vibraciones acústicas a través de las cuales recibimos las palabras, la información paralingüística, la banda sonora y los efectos especiales) y el canal visual (las ondas luminosas a través de las que recibimos imágenes en movimiento, pero también carteles o rótulos con textos escritos, etc.). En términos semióticos, [...] su complejidad reside en un entramado sígnico que conjuga información verbal (escrita y oral) e información no verbal, codificada según 
diferentes sistemas de significación de manera simultánea (Chaume 2004: 30).

Ambas MA y AVT están enmarcados dentro de los estudios de Traducción y, a su vez, parcialmente dentro de los estudios de Accesibilidad -Accessibility Studies AS-. Los estudios de Accesibilidad en el Contexto Digital incluyen un amplio espectro de ámbitos de conocimiento entre los que se encuentra el acceso en la interacción del usuario (Queiros et al., 2015), su experiencia (Aizpurua, Harper y Vigo 2016) o la interfaz (Hoareau y Satoh 2009), entre otros. En esta línea, enmarcamos las modalidades de Traducción e Interpretación Accesible en el contexto digital, dentro de la perspectiva universalista, como parte de los estudios de Accesibilidad e incluyendo la AVT y la MA.

\section{Acercamiento a una delimitación de las modalidades de traducción accesible en el entorno digital}

Las modalidades de Traducción e Interpretación Accesible en el entorno digital podrían definirse como aquellas que engloban los procesos de transmisión de información que parten de un texto origen enmarcado en un contexto digital y emiten un texto meta en un código que amplía el número de receptores al que originalmente pudiera estar destinado el texto origen, eliminando las barreras comunicativas, sensoriales y/o cognitivas (Arrufat 2020).

De esta manera, se entiende que las modalidades de Traducción e Interpretación Accesible abarcan la accesibilidad sensorial y cognitiva, mientras que la accesibilidad estructural necesaria para poder acceder a los dispositivos, así como aquellos aspectos técnicos relativos al desarrollo e interacción con la tecnología, no forman parte de esta área epistemológica. La traducción accesible se enfoca desde la creación textual intersemiótica y el uso de códigos. Por ello, a continuación, se definen y contextualizan las principales modalidades que hemos delimitado en un primer acercamiento: la descripción verbal, la interpretación a códigos visuales gestuales, la transcripción y la adaptación textual.

\subsection{La descripción verbal}

La descripción verbal es, por naturaleza, una actividad compleja, desde un punto de vista cognitivo, y de naturaleza semiótica intermodal (Braun 2007: 358). Consiste en la expresión verbal de la información visual presente y tiene por objeto principal facilitar el acceso al contenido a las personas con discapacidad visual. La descripción verbal ha sido ampliamente utilizada como sinónimo de audiodescripción (AD) (Soler 2012: 89) por su relación epistemológica con los estudios de traducción audiovisual (Mayoral Asensio 2005: 4; Jiménez Hurtado 2007; Cabezas Gay 2017: 37). No obstante, desde la perspectiva de la localización, esta modalidad de traducción se ha visto enriquecida con otros géneros textuales de carácter multimodal que también forman parte de la misma, como el texto alternativo y la descripción textual.

Existen dos teorías asentadas sobre la clasificación de la audiodescripción que atienden al ámbito de aplicación y al tipo de transmisión. La clasificación ofrecida por Díaz Cintas (2007b) establece una diferenciación entre la audiodescripción grabada para la pantalla, la audiodescripción grabada para audioguías y la audiodescripción en directo o semidirecto:

AD grabada para la pantalla: de programas audiovisuales con imágenes en movimiento, como películas, series de televisión, documentales, espectáculos, etc., independientemente del soporte en el que se distribuyen o comercializan (televisión, cine, DVD, Internet, reproductores móviles).

AD grabada para audioguías: de obras estáticas como monumentos, museos, galerías de arte, iglesias, palacios, exposiciones, entornos naturales y espacios temáticos en las que no hay imágenes en movimiento y en las que la experiencia táctil, o nuevas tecnologías que simulen este tipo de experiencia, tiene una gran importancia.

$\mathrm{AD}$ en directo o semidirecto: de obras teatrales, musicales, ballet, opera, deportes y otros espectáculos similares. También entran dentro de esta categoría los congresos y cualquier manifestación pública como los actos políticos (Díaz Cintas 2007b: 50).

Según el modo de transmisión, la segunda categorización consiste en la audiodescripción grabada y la 
audiodescripción en directo, una clasificación que se aplica en los Criterios de Accesibilidad al Contenido Web (WCAG 2.1) solo desde la modalidad pregrabada. Sin embargo, la audiodescripción en directo constituye un ejemplo más de buenas prácticas que permite el acceso a la información en eventos comunicativos emitidos en directo, como pueden ser un congreso, un evento político, una obra de teatro en streaming, visitas guiadas a museos, exposiciones y lugares del patrimonio cultural, ampliamente estudiados en los Estudios de Traducción e Interpretación (Luque Colmenero y Fernández Díez 2015; Orero 2016; Szarkowska et al., 2016a; Soler Gallego y Limbach 2016). Teniendo en cuenta que el entorno digital constituye un evento comunicativo complejo en el que confluyen distintos medios para transmitir el conocimiento, las modalidades tradicionales previamente expuestas confluyen con otras que cumplen con el mismo objeto a través de la descripción verbal: los textos alternativos y las descripciones textuales, expuestos a continuación.

En la siguiente taxonomía sobre la descripción verbal, definida como aquella en la que se expresa verbalmente la información visual presente con el objeto principal de facilitar el acceso al contenido a las personas con discapacidad visual, hemos diferenciado entre audiodescripción, textos alternativos y descripciones textuales por la diferenciación general que supone en el contexto de la accesibilidad al contenido digital y las pautas específicas que se establecen para cada técnica:

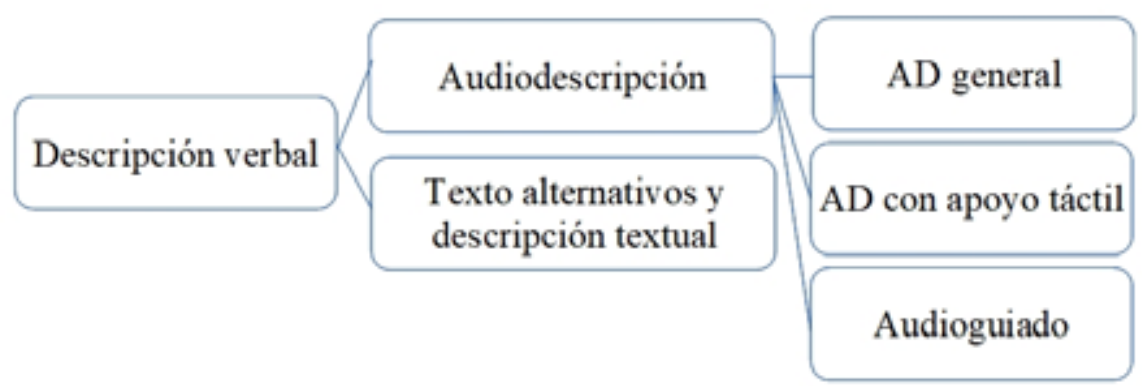

Figura 1. Esquema de la descripción verbal (elaboración propia)

\subsubsection{Audiodescripción}

La audiodescripción se define según la norma UNE 153020 (Asociación Española de Normalización y Certificación 2005: 4) de Audiodescripción para personas con discapacidad visual: requisitos para la audiodescripción y elaboración de audioguías, como:

Servicio de apoyo a la comunicación que consiste en el conjunto de técnicas y habilidades aplicadas, con objeto de compensar la carencia de captación de la parte visual contenida en cualquier tipo de mensaje, suministrando una adecuada información sonora que la traduce o explica, de manera que el posible receptor discapacitado visual perciba dicho mensaje como un todo armónico y de la forma más parecida a como lo percibe una persona que ve.

Pese a que esta definición bien podría abarcar a toda la modalidad, la norma UNE solo hace mención explícita a la audiodescripción y el audioguiado. Además, esta definición habla de un conjunto de técnicas y habilidades cuando la audiodescripción ( $\mathrm{AD}$ ) puede ser considerada como una técnica en sí misma, que se adapta a la obra. Por este motivo, hemos seleccionado otra definición recientemente aportada por Vázquez (2019) para la AD fílmica:

Un sistema de apoyo a la comunicación que aporta los datos contenidos en el lenguaje visual de una película, permitiendo su comprensión, mediante una banda sonora de locuciones integradas armónicamente en el sonido de la película (Vázquez 2019: 45). 
Esta definición hace especial hincapié en la AD como sistema de apoyo a la comunicación y a la importancia de la integración armónica de la locución de la $\mathrm{AD}$ en la pista de audio de la película. En el contexto digital, encontramos más tipos de productos audiovisuales. Además de la película, existe un amplio espectro de materiales audiovisuales, por lo que podríamos adaptar la definición de la siguiente manera: La audiodescripción en el contexto digital es un sistema de apoyo a la comunicación que aporta los datos contenidos en el lenguaje visual de un texto monomodal o multimodal, permitiendo su comprensión, mediante una banda sonora de locuciones integradas armónicamente en la pista de audio.

La $A D$ general, sin exploración táctil, ha sido ampliamente estudiada en la última década (Jiménez 2007; Álvarez de Morales, Limbach y Luque 2012; Soler 2012; Soler y Chica 2014; Jiménez y Soler 2015; Vázquez 2019). Consiste en describir la información visual a través de una locución que emplea los silencios para insertarla o los alarga para poder ofrecer la información necesaria a través de una audiodescripción extendida. La AD se encuentra en una fase de cambio y evolución debido a las nuevas posibilidades que ofrece la tecnología. Uno de los aspectos fundamentales que hemos podido observar en la definición es la importancia de que forme parte del mensaje audiovisual como un todo armónico, algo presente en las emisiones de plataformas de streaming como Netflix o RTVE. Al locutar la pista de AD, un técnico de sonido la incorpora siguiendo las pautas de montaje de las producciones audiovisuales, la pista de audio original para facilitar el disfrute sonoro del usuario, y esta parece ser la manera más lógica de realizar este proceso. Sin embargo, esta situación difiere de la realidad cuando la película se emite en la televisión, ya que las posibilidades de personalización de la accesibilidad a la hora de activar o desactivar la audiodescripción o el subtitulado para personas sordas (SpS) ha conducido a los canales a emitir las pistas de audio por separado, siendo el propio televisor el que realiza la mezcla para su emisión. Esto produce que las experiencias de los usuarios sean, en muchas ocasiones, negativas, ya que el sonido de las pistas se emite con diferente potencia y produce una sensación disruptiva en el usuario (Martos 2019). Vázquez (2019) señala que la $\mathrm{AD}$ es un arte y que no se debe olvidar la importancia que tienen el resto de sonidos e, incluso, el silencio en un producto audiovisual. Por ende, la accesibilidad debe cuidar la armonía del material como un todo para que la calidad de la experiencia del usuario sea óptima.

La audiodescripción con apoyo táctil es una audiodescripción complementada con códigos táctiles. Este hecho se ve reflejado en sus características estructurales discursivas y semánticas (Cabezas Gay 2017: 187). Las audiodescripciones locutadas suelen tener como objeto permitir una exploración táctil autónoma del material, mientras que las audiodescripciones en directo se realizan acompañados de un profesional que ofrece la información in situ, por ejemplo, la que se ofrece en las visitas guiadas a los museos. Aunque la exploración táctil se suele emplear en ámbitos específicos como el museístico o el educativo, no hemos especificado contextos de uso en el presente trabajo, sino que hemos abordado las características que definen a las diferentes modalidades en el contexto de estudio.

La audiodescripción extendida es aquella que se añade al producto audiovisual, deteniendo el vídeo, para poder incluir la descripción auditiva que resulta imposible incluir en las pausas del diálogo (Thomson 2018). Se corresponde con el nivel más alto de los criterios de conformidad de las Pautas de Accesibilidad para el Contenido Web y puede estar locutada dentro de la misma pista de audio o reproducirse, al igual que los textos alternativos, con herramientas específicas como STARTIT o AuDIVA (Pantula y Kuppusamy 2019).

Elaudioguiado tiene un carácter espacial. Según la norma UNE 153020 (Asociación Española de Normalización y Certificación 2005: 4), la audioguía se define como una «descripción sonora estructurada que permite a las personas con discapacidad visual el acceso a los bienes del patrimonio artístico, cultural y natural: exposiciones, monumentos, espacios naturales y temáticos». Por ello, se establece que entre los contenidos de la audioguía se han de incluir las instrucciones sobre el dispositivo electrónico, la información relativa a la seguridad del recinto, la descripción del espacio (entrada, salida, ruta de circulación, ubicación de los servicios útiles, ubicación de los materiales accesibles, ubicación de los planos) y la descripción de los objetos o entornos, es decir, todas aquellas instrucciones que facilitan la orientación y movilidad de las personas con diversidad funcional visual (DFV) en espacios abiertos y cerrados (Soler y Limbach 2016: 33). 


\subsubsection{Descripción textual y texto alternativo}

En este apartado analizaremos dos modalidades de traducción intersemiótica que encontramos específicamente en el contexto digital: la descripción textual y/o el texto alternativo que se añade a los elementos para ofrecer una información textual adicional sobre el contenido que no es textual o que es necesario ampliar para facilitar su comprensión y uso si no se tiene acceso a la información visual (Shaqoor y Kuppusamy 2018). A diferencia de los textos alternativos, que permiten introducir descripciones cortas de los elementos, las descripciones textuales tienen como función añadir toda aquella información complementaria que se considere necesaria en un espacio más amplio y flexible a través de un enlace a otra página o en la misma página.

Los textos alternativos suelen tener una extensión máxima de 120 caracteres y su función consiste en facilitar la descripción de imágenes, botones, enlaces, información relevante para asegurar la interacción autónoma en el entorno digital, catpchas, etc. En este sentido, los procesos de traducción responden a la función semiótica de la significación de la imagen en la que el texto resultante debe responder al objetivo de la imagen, es decir, cada elemento al que se le asocia una descripción textual y/o un texto alternativo supone una construcción semiótica autónoma dentro del universo de las comunicaciones visuales (Eco 1975). Según Eco, los textos visuales no son analizables ulteriormente en signos, los objetos no se pueden duplicar, sino que realizamos una reproducción parcial del mismo a través de un cambio de código atendiendo a sus cualidades funcionales y consiguiendo como resultado un texto hipocodificado. En voz de Barthes, semiólogo afanado por interpretar los signos desde la metáfora de un viaje a Japón:

Las calles de esta ciudad no tienen nombre. Existe una dirección escrita, pero sólo tiene un valor postal, se refiere a un catastro (por barrios y por bloques, de ningún modo geométricos) cuyo conocimiento es accesible al cartero, no al visitante: la ciudad más grande del mundo está, prácticamente, inclasificada, los espacios que la componen en detalle están innominados (Barthes 1970: 52).

La traducción intersemiótica de códigos visuales hacia códigos lingüísticos conforma todo un viaje que poco a poco se va configurando y sistematizando para acercar la información al usuario.

La longitud máxima de un texto alternativo suele ser de 120 caracteres si se utiliza el atributo ALT. Según Tercedor et al. (2007a: 74), los principales problemas de accesibilidad provienen de las siguientes situaciones:

- las imágenes no ofrecen descripciones textuales

- las descripciones textuales son incompletas (poco precisas o ambiguas)

- las descripciones textuales no reflejan los aspectos relevantes de la imagen ni su función.

La adecuación del texto alternativo depende, principalmente, de la función. Según el Mapa de decisión para proporcionar textos alternativos adecuados a las imágenes (Carreras 2014), el desarrollo de un texto alternativo acorde se puede determinar teniendo en cuenta la imagen y su función.

Por un lado, si la imagen es o forma parte de un enlace o botón, debemos preguntarnos también si la imagen es el único elemento dentro del enlace; un botón de tipo imagen, que incluye texto; o, un mapa de imagen. En caso afirmativo, el texto alternativo debe hacer referencia a la función de la imagen, como analizaremos uno por uno a través de los siguientes casos:

a) En el caso de los logos, iconos, imágenes y botones de tipo imagen en los que esta no contenga texto, se debe introducir la función de la imagen.

Por ejemplo, en la página web de la Universidad de Granada, el logo debe incluir un texto alternativo que haga referencia a la función de esa imagen, en este caso, hacer clic sobre el logo nos permite acceder a la página de inicio. Un texto alternativo funcional sería el siguiente:

<img src="logo.png" alt="Página principal de la web de la Universidad de Granada" / >

En el siguiente ejemplo, hemos seleccionado el icono de la lupa que aparece en la parte superior derecha para realizar búsquedas dentro de la página. En este caso, un texto alternativo que cumpla con la funcionalidad de la imagen no sería la descripción de una lupa, sino que debemos enfatizar en la acción de buscar:

$<$ input type="image" src="buscar.gif" alt="Buscar"/> 
En el caso de los iconos, imágenes o botones de tipo imagen que contienen texto debemos introducir dentro del texto alternativo la función de la imagen, que suele coincidir con el texto que aparece en la imagen. Por ejemplo:

$<$ img src="recibirmensajes.gif" alt="Recibir mensajes"/>

b) Los mapas de imágenes son una casuística un poco diferente a los anteriores, ya que son imágenes más complejas y, por ello, deberemos identificar el contenido, además de la función. Por ejemplo, en un mapa de imágenes en el que se ven representadas las diferentes provincias de España en el que se puede hacer clic para descargar los códigos de cada provincia, un buen ejemplo de texto alternativo para el mapa de imágenes sería el siguiente:

$<$ img src="España.gif" usemap="\#map1" alt="Mapa de España. Seleccione una provincia para descargar los códigos">

c) En aquellos casos en los que la imagen es o forma parte de un enlace o botón, pero no es el único elemento, encontramos dos casuísticas diferentes: por un lado, puede que la imagen aporte información adicional al texto del enlace y, por otro, puede que sea una imagen decorativa que no aporte información adicional. A continuación, exponemos un ejemplo de cada tipo para ver cómo se deben abordar cada uno de ellos.

Si la imagen es complementaria a la información textual y nos facilita información sobre el tipo de documento, un texto alternativo eficaz podría ser:

$<\mathrm{a}=$ href="Memoriaverifica.html" Memoria verifica Óptica y Optometría $<$ img src="icon.gif" alt= "en formato $\mathrm{PDF}^{\prime} /></ \mathrm{a}>$

En aquellos casos en los que la imagen es decorativa no se debe incluir el atributo o definir que la imagen es decorativa en la hoja de estilo en cascada CSS (Cascadind Style Sheet). En el siguiente ejemplo, la imagen contiene, además del texto del Grado en Óptica y Optometría, una flecha decorativa y, por este motivo no se debe incluir un texto alternativo de esa imagen, sino que la solución en el código sería la siguiente:

$<$ a href="optica.html" > <img src="icon.gif" alt=“"/> Grado en Óptica y Optometría $<$ a/ $>$

Por otro lado, también encontramos imágenes que no forman parte de un enlace o botón y, en estos casos, debemos preguntarnos igualmente si la imagen es decorativa o si, por el contrario, aporta información adicional.

d) Si la imagen es decorativa, sucede como en el ejemplo anterior y no se debe incluir el atributo title a menos que esté vacío o definir en la CSS que la imagen es decorativa. Por ejemplo, en la página principal de la web del Grado en Traducción e Interpretación de la Universidad de Granada, la imagen que aparece desde un punto de vista funcional es decorativa y no se debe añadir un texto alternativo.

e) Es de especial interés para el traductor y para los diseñadores de contenidos aquellas imágenes que aportan una información adicional y que no forman parte de un enlace o botón. En estos casos, los textos alternativos son más complejos y siguen un procedimiento diferente al anterior.

Si la imagen corresponde a una expresión artística cuya función es crear una experiencia sensorial, es conveniente incluir un texto descriptivo adicional al texto alternativo para poder dar esta información. El texto alternativo debe dar una descripción concisa de la imagen que, en caso de tener un nombre aceptado, debe coincidir con el texto alternativo. Por ejemplo, la obra La Muerte del Príncipe de Viana. Vicente Poveda y Juan, perteneciente al Museo del Prado y ubicada en el Salón Rojo del Hospital Real de la Universidad de Granada, tiene un título catalogado y, por tanto, su texto alternativo debe hacer referencia al mismo y a su autor: <img src="muertedelprincipe.jpg" alt="Cuadro La Muerte del Príncipe de Viana de Vicente Poveda y Juan." />

En aquellos casos en los que la imagen no tiene un nombre conocido o tiene una función diferente, se debe realizar una breve descripción que identifique el contenido y la función de la imagen. Por ejemplo, la imagen de portada de la página del Archivo Universitario coincide con una fotografía de la torre de la Catedral de Granada y, en ese caso, un posible texto alternativo para la imagen podría ser: 
$<$ img src="portadaarchivouniversitario.jpg" alt="Imagen de portada de Archivo Universitario, fotografía en blanco y negro de la torre de la Catedral de Granada." />

f) En aquellos casos en los que la imagen no tiene por objeto crear una expresión sensorial podemos encontrar que sea parte de una prueba o test que quedaría invalidado si se describiera la imagen como en el caso de los captchas, que permiten comprobar si el usuario es una persona o una máquina. En estos casos, el texto alternativo debe hacer referencia a la función y describir el propósito del captcha:

<img src="captcha.png" alt="Introduce en el campo la suma de las dos cifras">

Si la imagen se puede describir con menos de 150 caracteres, podemos encontrar diferentes casos en los que se utiliza el texto alternativo como imágenes, imágenes de texto e imágenes que incluyen un texto no decorativo.

g) El texto alternativo que se incluya en las imágenes debe trasmitir la información de la imagen. En el siguiente ejemplo de la noticia de Canal UGR: Más de 40 personas con discapacidad recogen sus diplomas de participación en los programas de prácticas de la UGR, podemos ver un ejemplo de texto alternativo:

<img src="entregadiplomas2.png" alt="Fotografía del acto en la que la Rectora entrega el diploma a uno de los participantes del programa de prácticas”/>

h) Las imágenes de texto deben incluir en el texto alternativo el texto de la imagen, no obstante, por motivos de accesibilidad es preferible establecer el texto con el estilo definido en la CSS. Por ejemplo:

$<$ img src="canalugr.png" alt="Canal UGR"/>

i) Las imágenes que incluyen un texto no decorativo deben incluir la información que se transmite en la imagen y en el texto. En este caso, al igual que en el anterior, se recomienda que no se incluyan imágenes de texto.

Por ejemplo, ante una miniatura de la noticia de Canal UGR sobre la exposición el Museo del Prado en la Universidad de Granada, en la que han utilizado como fondo para el texto un fragmento del óleo sobre lienzo Lampecia y Febe (fábula) de Antonio Muñoz Degrain, una posibilidad de texto alternativo sería la siguiente:

<img src="miniaturamuseoprado.png" alt="Exposición el Museo del Prado en la Universidad de Granada, cartel elaborado sobre el óleo de Muñoz Degrain Lampecia y Febe"/>

j) En aquellos casos en los que las imágenes forman parte de una serie contigua que transmite una información en conjunto el texto alternativo debe transmitir la información final de este conjunto. Por ejemplo, ante la valoración de un restaurante de cuatro y medio sobre cinco en la página web de TripAdvisor aparecen cuatro círculos y medio y una posibilidad para aplicar el texto alternativo para facilitar un significado funcional para el usuario supone describir el conjunto de imágenes:

<img src="1.jpg" alt="Puntuación de cuatro y medio sobre cinco" img src="2.jpg" alt="” img src="3.jpg" alt="' img src="4.jpg” alt="' img src="5.jpg" alt="'>

k) Finalmente, encontramos aquellas imágenes que no se pueden describir con un texto de menos de 150 caracteres como pueden ser los diagramas o las infografías. En estos casos, el texto alternativo debe identificar el contenido de la imagen o una breve descripción mientras que se recomienda proporcionar una descripción larga para expresar de manera completa dicho contenido. Por ejemplo, ante una infografía del Departamento de la Señal, Telemática y Comunicaciones de la Universidad de Granada, podríamos identificarla a través del texto alternativo como:

<img src="infografia.jpg" alt="Infografía del Departamento TSTC de 2010 a 2017">

En este caso, se debería optar por las descripciones textuales como recurso complementario, ya que permiten añadir una descripción más extensa que los textos alternativos. Esta descripción se puede añadir en otra página enlazada antes o después de la imagen o en la misma página, mediante el atributo LONGDESC.

Desde una aproximación traductológica, el texto alternativo de cada elemento debe traducirse a la lengua meta y debe resumir el contenido (Tercedor y Jiménez Crespo 2007). En este sentido, Tercedor y Jiménez Crespo añaden que se debe tener en cuenta que la comunicación multimodal que ofrece permite realizar tareas cognitivas 
más complejas, como procesos conceptuales o la comprensión lingüística (Tercedor y Abadía 2005).

El desarrollo de la automatización en los procesos de evaluación de accesibilidad está promoviendo que cada vez sean más los estudios enfocados a nuevos sistemas de evaluación automáticos de textos alternativos (Shaqoor y Kuppusamy 2018; Duarte, Duarte y Carriço 2019). Estos sistemas permiten evaluar los textos que pueden mejorar el posicionamiento web de las páginas y trabajan para detectar errores como la repetición de la descripción de la imagen en el texto alternativo o la ausencia de traducción a la lengua meta del texto alternativo asociado a la imagen, un error que suele suceder por el uso compartido de librerías de imágenes.

A lo largo de este apartado hemos podido observar las características que delimitan los diferentes tipos de audiodescripción, texto alternativo y descripciones textuales en el entorno digital. En esta línea, nos gustaría subrayar que la principal diferencia existente entre la audiodescripción y los textos alternativos y descripciones textuales es que la audiodescripción suele estar locutada, ya sea en directo o pregrabada, mientras que los textos alternativos y las descripciones textuales están diseñados para ser interpretados por lectores de pantalla como NVDA o JAWS. Estos programas permiten que el usuario los pueda regular según sus preferencias, como aumentar o reducir la velocidad de la voz, cambiar la voz e, incluso, cambiar de manera automática el idioma de lectura. Por el contrario, las audiodescripciones suelen ser pistas de audio locutadas que se insertan como archivo o enlace en la página o en el programa, lo que limita que se puedan adaptar a las preferencias de los usuarios.

\subsection{La interpretación a códigos visuales gestuales}

Los códigos visuales gestuales son sistemas lingüísticos que se caracterizan por el uso de signos manuales. Han sido objeto de estudio científico especialmente a partir del siglo XX (Stokoe 1960; Friedman 1976; Báez Montero 2010). Las diferencias entre las lenguas auditivas orales y las visuales gestuales son visibles por los canales de comunicación que emplean y su forma de expresión.

A continuación, se analizan los principales códigos visuales-gestuales según la siguiente clasificación:

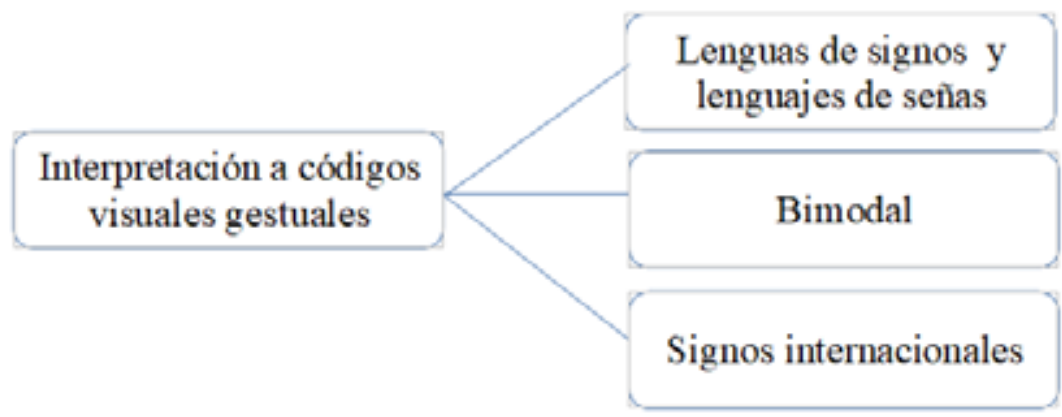

Figura 2. Esquema de la interpretación a códigos visuales gestuales (elaboración propia)

\subsubsection{La lengua de signos o lenguaje de señas}

Las lenguas de signos o lenguajes de señas están directamente relacionados con la accesibilidad a la información y a la comunicación por los usuarios principales de los mismos. Son utilizados por personas sordas, por personas sordociegas y por aquellas que presentan dificultades en el habla. Por este motivo, existen variaciones en relación al modo de expresión y comunicación que han permitido adaptarla para eliminar las barreras comunicativas, como las visuales que las personas con algún tipo de pérdida de visión pueden afrontar. Estas modalidades son la lengua de signos en el campo visual (visión en túnel, visión periférica o a corta distancia) y lengua de signos apoyada (bimanual, mono manual o apoyada en la muñeca). La diversidad de los usuarios en el acceso 
a la información a través de los códigos visuales gestuales está muy presente en la sociedad y es necesario dar visibilidad a esta situación para poder ofrecer soluciones efectivas para todas las personas (De los Santos Rodríguez y Lara Burgos 2004).

Las lenguas de signos tienen una relación cultural que influye en la concepción visual espacial de los usuarios. Por ejemplo, la manera en la que nos sentamos en Occidente difiere de la forma de sentarse en los países asiáticos, por lo que la iconocidad de los signos que representan esta acción muestra diferentes posturas o maneras de identificar visualmente esta acción en las lenguas de signos de los países. En las lenguas de signos americana y rusa, se hace referencia a la flexión de las piernas al sentarse sobre una superficie:

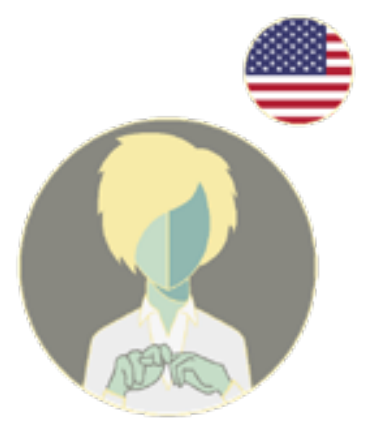

Figura 3. Signo de sentarse en lengua de signos estadounidense

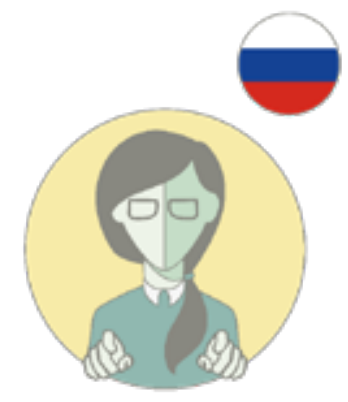

Figura 4. Signo de sentarse en lengua de signos rusa

En lengua de signos británica, el signo hace referencia a apoyar las manos sobre una mesa al sentarse:

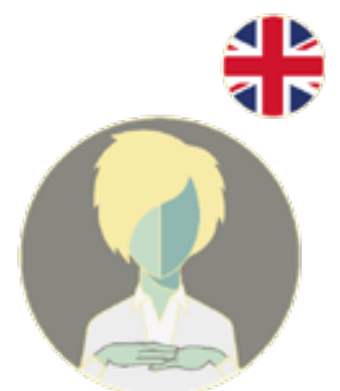

Figura 5. Signo de sentarse en lengua de signos británica 
En lengua de signos española y francesa, este signo hace referencia a apoyar los glúteos sobre una superficie:

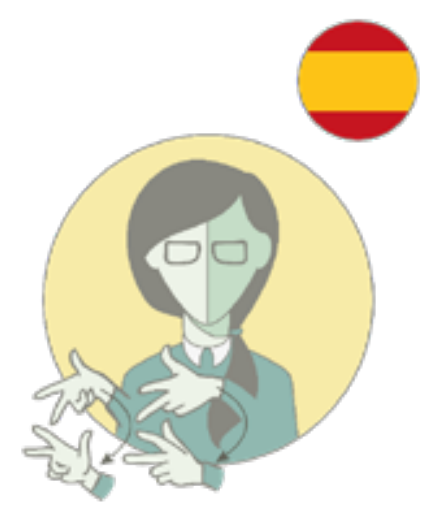

Figura 6. Signo de sentarse en lengua de signos española

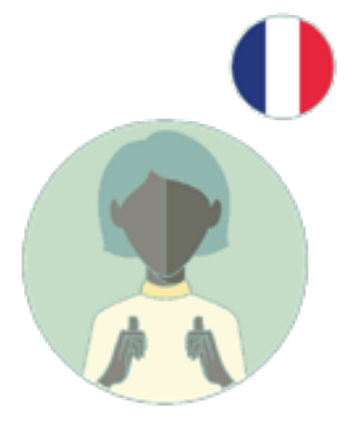

Figura 7. Signo de sentarse en lengua de signos francesa

Sin embargo, en lengua de signos china, el signo hace referencia a la postura en la que habitualmente se sientan, sobre las rodillas:

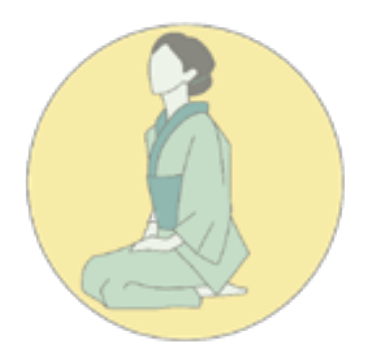

Figura 8. Imagen ilustrativa sobre la cultura china 


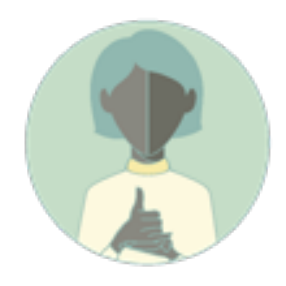

Figura 9. Signo de sentarse en lengua de signos china

Uno de los factores más influyentes en el desarrollo lingüístico de las diferentes lenguas de signos a nivel internacional es el reconocimiento legal por parte de los estados como una lengua oficial. Este paso constituye un elemento clave en el desarrollo de un cuerpo normativo que garantice los derechos lingüísticos y culturales de la comunidad de referencia (Amezcua-Aguilar y Amezcua-Aguilar 2018). Algunos países han sido pioneros en el reconocimiento de las lenguas de signos dentro de sus Constituciones como Finlandia y Uganda en 1995, Sudáfrica en 1996, Portugal en 1997, la República Checa y Ecuador en 1998, Venezuela en 1999, Austria en 2005 y Kenia en 2010. El caso de España es diferente y está relacionado con la incorporación al marco normativo de una ley específica que reconoce las lenguas de signos españolas. El tipo de reconocimiento legal de la lengua de signos en un país condiciona tanto su desarrollo como la garantía de derechos humanos de las personas signantes. Por otro lado, la lengua de signos no está limitada como lengua materna exclusivamente a las personas sordas y su entorno cercano, sino que es una vía comunicacional utilizada por diferentes colectivos dentro de los Sistemas Aumentativos y Alternativos de Comunicación, lo que favorece que un mayor número de personas pueda comunicarse con su entorno utilizando la lengua de signos como vehículo comunicativo (AmezcuaAguilar y Amezcua-Aguilar 2018).

\subsubsection{El sistema bimodal}

El término bimodal fue introducido por Schlesinger (1978) para designar la asociación de dos modalidades: signada y hablada. El bimodal es un sistema lingüístico creado con fines educativos. Desde esta perspectiva, está considerado como un sistema aumentativo y alternativo que emplea la estructura de la lengua oral con signos de la lengua de signos, además del uso del dactilológico y de signos artificiales. Los sistemas alternativos son aquellos que sustituyen el lenguaje, como la escritura y los pictogramas. Mientras que los sistemas aumentativos se emplean para añadir una mayor eficacia a la comunicación oral y, por ello, el empleo de diferentes canales constituye un estímulo para mejorar la comprensión y la percepción de los conceptos especialmente durante la etapa educativa y en la vida cotidiana de muchos usuarios (Monfort 2006). También, es considerado como un pidgin, pues este se define como un código simplificado que parte de dos o más lenguas sin llegar a ser la lengua materna de ninguna comunidad y, en este caso, los sistemas bimodales tienen como base dos lenguas: la lengua oral y la lengua signada.

El bimodal, por tanto, consiste en expresar un mismo significado o concepto mediante dos sistemas de códigos independientes: el acústico, dirigido a la audición, y el visual, dirigido a la vista. En ambos casos el significado o concepto es la representación de algo distinto a lo visto y a lo oído, o sea, se puede acceder al mismo significado o concepto por cualquiera de las dos modalidades independiente o simultáneamente (Torres y Sánchez 2002: 4).

Como hemos indicado anteriormente, el sistema bimodal requiere de otros elementos además de los signos de la lengua de signos, por ejemplo, los artículos definidos en español no tienen un signo en LSE, lo que requiere que se emplee el dactilológico para introducirlo en el sistema bimodal español e, igualmente, el género tampoco se define en muchos signos y, para expresarlo en bimodal, es necesario añadir el signo que indica el género 
después del signo del sustantivo.

El principio básico que subyace a este código es que a cada palabra le corresponde un signo, no obstante, hemos visto dos ejemplos en los que es necesario enriquecer la expresión gestual para completar el significado. El bimodal es un sistema que se emplea en diferentes países y que tiene como objeto principal favorecer la adquisición de la lengua oral a diferentes colectivos, como para personas del espectro autista, personas con discapacidad intelectual o personas con discapacidad auditiva, entre otros.

\subsubsection{Los signos internacionales}

Los Signos Internacionales tienen su origen en las iniciativas de la Federación Mundial de Sordos (FMS), creada en 1951. La federación realiza cada cuatro años un congreso mundial en el que además se reúne la Asamblea General, el órgano responsable de las políticas de la Federación y de los grupos de trabajo que se focalizan en diferentes temas de investigación. En 1975, la Comisión de Unificación de Signos crea un sistema de comunicación artificial llamado Gestuno. Este sistema artificial es el primero que favorece el desarrollo y difusión de signos internacionales para favorecer la comunicación entre personas sordas de diferentes países (Moreno, Pinedo y Rodríguez 2006). Desde una perspectiva lingüística, los signos internacionales no se consideran una lengua materna, ya que no se utilizan en los entornos cotidianos, sino que se ha creado desde diferentes lenguas de signos que entran en contacto por un contexto internacional y, por ello, se considera un pidgin. Por este mismo motivo, no es una lengua artificial, como el esperanto, ya que no ha sido creada expresamente como tal, sino que ha seguido una evolución natural tras el contacto internacional de personas sordas signantes de diferentes países y, también se descarta que sea una lengua criolla, ya que no es la lengua materna de ninguna comunidad.

El contexto de uso de los signos internacionales se limita a los encuentros realizados en las entidades internacionales como la Organización de las Naciones Unidas, la Organización Mundial de la Salud o en reuniones del Parlamento Europeo.

Los signos internacionales se pueden definir como una especie de pidgin que se produce cuando las lenguas de signos entran en contacto, presentando un léxico y unas gramáticas reducidas o simplificadas y normalmente utilizados a un nivel básico y en contextos limitados (Estévez 2009, sección 3: ubicación actual del SSI).

El empleo de los signos internacionales y su investigación tienen un carácter institucional e internacional por los contextos que delimitan su uso. Por este motivo, la variedad léxica y el empleo de la gramática puede variar considerablemente según los usuarios que lo utilicen, ya que el préstamo léxico e, incluso, la pantomima, son recursos frecuentes en este sistema de comunicación:

El préstamo léxico se define como el proceso por el cual una lengua o sistema de comunicación, adquiere una palabra que no tenía y que pertenece al léxico de otra lengua. Este proceso se desarrolla durante un tiempo determinado, variable, que corresponde a la codificación más o menos rápida de esa palabra en la lengua. Entre los factores que llevan a este proceso es la necesidad de nombrar nuevas cosas, nuevos conceptos o la necesidad de utilizar determinadas palabras para hacerse comprender. Mientras que la pantomima se utiliza para crear un signo o significado, utilizando mayor espacio (Estévez 2009: sección 3, ubicación actual del SSI).

Además de estos recursos, es frecuente el empleo de paráfrasis y perífrasis para facilitar la explicación de los conceptos. Los signos internacionales están en constante expansión y gracias al desarrollo de las redes sociales y la facilidad actual para comunicarnos, cada vez son más las transferencias de neologismos y signos de otras lenguas influyentes como la lengua de signos estadounidense.

\subsection{La transcripción}

En este apartado sobre la transcripción, hemos diferenciado la transcripción textual y el subtitulado, dos modalidades cada vez más presentes como herramientas de accesibilidad en el entorno digital. 


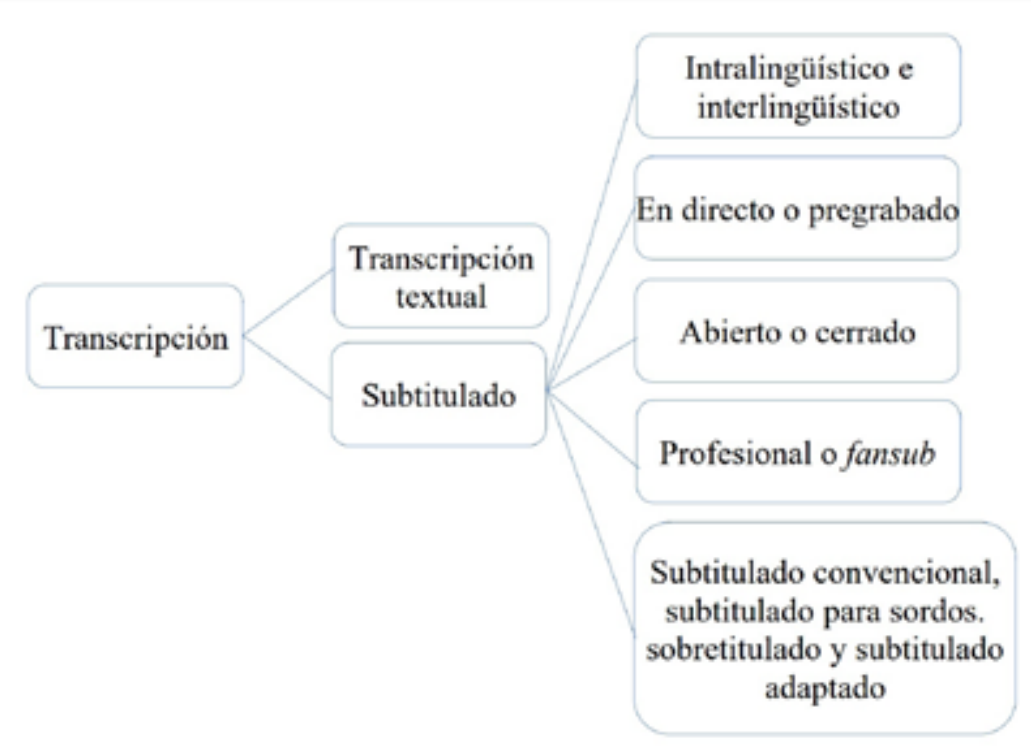

Figura 10. Esquema de la transcripción (elaboración propia)

Desde un punto de vista semiótico, la transcripción en entornos digitales se podría definir como la práctica por la que se traduce, transcribe y/o translitera un texto oral o manuscrito a un texto digital escrito, que puede estar, a su vez, enriquecido con información paralingüística y extralingüística con el objeto de facilitar la información a través del canal visual, auditivo o táctil.

La sincronía de los elementos acústico y visual es relevante tanto en la transcripción textual como en el subtitulado, ya que en ambas permite que el usuario pueda acceder a la información con el mínimo desfase (Talaván 2009). No obstante, las transcripciones textuales no siempre incluyen indicadores temporales. Los tres canales de percepción -visual, auditivo y táctil- pueden facilitar la información del texto digital a través de diferentes aplicaciones y tecnologías de asistencia atendiendo a la configuración del usuario: emitiendo la información palabra a palabra, en macrofuente, con preferencias específicas de voz o de emisión en pantalla, según la configuración recogida en la línea braille, etc.

Las transcripciones pueden ser producidas por seres humanos o por un programa (Furini 2016). Las realizadas por personas requieren de mayores recursos económicos y temporales, mientras que las que realizan los programas de reconocimiento de voz automático necesitan unas condiciones idóneas para conseguir una mayor precisión (Wald 2011). La tendencia actual está orientada hacia el uso de transcripciones realizadas por programas de reconocimiento de voz posteditadas por personas (Liem, Zhang y Chen 2011) y el rehablado, que ha mejorado considerablemente gracias al desarrollo tecnológico. En este sentido, las últimas investigaciones apuntan que los programas ofrecen una calidad suficiente como para utilizarlo como herramienta autónoma sin postedición (Arzelus et al., 2018: 267).

En el contexto digital, cada vez son más las posibilidades que se ofrecen para expresar la información sonora a través de un texto y este, a su vez, posee una gran flexibilidad para que el usuario pueda acceder a través de diferentes tecnologías de asistencia. Así pues, si tenemos en cuenta la transcripción, debemos hacer hincapié en que nuestra intención no es delimitar sus características sino reflejar muchas de las posibilidades que ofrecen a los usuarios gracias al avance de la tecnología y al desarrollo de programas y aplicaciones.

\subsubsection{La transcripción textual}

Son numerosos los colectivos que pueden tener dificultades para escuchar la información sonora, desde personas con discapacidad auditiva, dislexia o movilidad reducida, para tomar apuntes mientras escuchan el audio, a personas con diferente lengua materna, personas mayores o niños, para entender la forma en la que habla el interlocutor (Federico y Furini 2012). Del mismo modo, las personas con discapacidad visual pueden encontrar dificultades para acceder a la información de un texto visual digital o manuscrito. 
Hemos querido incluir las transcripciones de textos manuscritos a textos digitales por su relevancia en el acceso y recuperación de la información. Tradicionalmente, las transcripciones de manuscritos se han realizado por profesionales para garantizar su calidad, sin embargo, cada vez son más los programas de reconocimiento óptico de caracteres y las plataformas de crowdsourcing, en las que voluntarios o personas que perciben pequeñas remuneraciones a través de plataformas como Mechanical Turk, CrowdFlower, Transcribe Bentham o AnnoTate, se ofrecen para realizar esta función (Doan, Ramakrishnan y Halevy 2011).

Según Claus Huitfeldt y Sperberg-McQueen (2008), la calidad de una transcripción debería considerarse desde una perspectiva heurística, lo que conlleva tener en cuenta tanto su función como el destinatario objetivo. Ante un mismo texto origen, el texto meta debería variar según las necesidades del público objetivo: personas con sordoceguera, personas con discapacidad auditiva, personas con discapacidad visual, personas con dislexia, etc. En esta línea, la tecnología puede facilitarlo a través de sus posibilidades de configuración según las preferencias del usuario: tipografía, tamaño de letra, contraste, emisión en pantalla palabra a palabra ajustando la velocidad de emisión en pantalla e, incluso, reproducción del texto a voz. La situación de accesibilidad en eventos que subtitulan en directo las intervenciones es cada vez más flexible y comienzan a introducir programas o páginas web que se adaptan a los dispositivos de los usuarios para emitir el texto del subtitulado en las pantallas de cada asistente.

\subsubsection{El subtitulado}

Continuamos con el análisis del subtitulado. Según Martínez (2015), el subtitulado es un área de investigación en constante expansión y desarrollo, lo que promueve que desde la traductología se apueste firmemente por el estudio de sus coordenadas lingüísticas y cognitivas, así como la relación entre el acceso al conocimiento y la tecnología (Díaz Cintas 2007a). El subtitulado fílmico es definido por este autor como:

Práctica que consiste en ofrecer, generalmente en la parte inferior de la pantalla, un texto escrito que pretende dar cuenta de los diálogos de los actores, así como de aquellos elementos discursivos que forman parte de la fotografía (cartas, pintadas, leyendas, pancartas, etc.) o de la pista sonora (canciones, voces en off, etc.) (Díaz Cintas 2007a: 8).

El subtitulado es una modalidad de traducción que consta de numerosas prácticas. Por este motivo, se ha realizado un esfuerzo por establecer clasificaciones atendiendo a aspectos técnicos, lingüísticos, pragmáticos o técnicos, entre otros (Martínez 2015). En la siguiente propuesta, nos hemos basado en la clasificación de Martínez, delimitando los tipos de subtítulos según los siguientes parámetros:

a) Lingüísticos: lengua del texto de origen y meta.

b) Momento de elaboración-emisión del subtitulado.

c) Flexibilidad en la activación.

d) Persona que los elabora.

e) Formato.

A continuación, analizamos cada parámetro y las subcategorías a las que pueden dar lugar cada uno.

Atendiendo a parámetros lingüísticos, el subtitulado puede ser intralingüístico, si el texto origen y el texto meta del subtitulado comparten el mismo código lingüístico o interlingüístico, si se realiza una traducción de una lengua a otra. Según Tercedor et al. (2007b), la subtitulación es un proceso de adaptación intra o interlingüística de un texto oral para ser leído siguiendo unas restricciones de espacio y tiempo. No obstante, estas categorías no son excluyentes entre sí, ya que los subtítulos bilingües se encuentran en numerosos recursos multimedia. Este tipo de subtitulado es cada vez más frecuente por las posibilidades que tienen como herramienta de aprendizaje de idiomas (Talaván 2009) y en lugares donde existen dos o más lenguas oficiales como Bélgica, donde se producen programas subtitulados en francés y flamenco; o, Marruecos, donde se pueden visualizar en francés y árabe. Del mismo modo, también son frecuentes en congresos y eventos internacionales.

Atendiendo al momento de elaboración y emisión del subtitulado, encontramos los subtítulos en directo, elaborados y lanzados en el momento de emisión del producto audiovisual; y, los subtítulos pregrabados o 
preparados. En ambos se puede apreciar cada vez más la influencia de la tecnología a través del uso de sistemas de reconocimiento de voz y de rehablado (Romero-Fresco 2013).

Atendiendo a la flexibilidad en la activación, encontramos dos tipos de subtítulos. Los subtítulos incrustados o subtítulos abiertos son aquellos que no se pueden desactivar ni modificar, ya que están superpuestos en el producto audiovisual (Martínez 2015). Este tipo de subtítulos es frecuente en redes sociales. Los últimos estudios realizados muestran la importancia de la duración en pantalla, pues la disminución de la velocidad de emisión incrementa la carga cognitiva y la frustración para los usuarios (Szarkowska et al., 2016b). Los subtítulos cerrados son aquellos que se pueden modificar según las preferencias de los usuarios, activar y desactivar. Este tipo de subtitulado puede estar en diferentes formatos como LRC (.lrc) para letras de canciones, SubViewer y SubRip (.sub y .srt) como formatos estándar, SubStation Alpha (.ssa y .ass) para subtítulos fansub y WebVTT (.vtt) para HTML5. Este último formato, recomendado por el W3C, es cada vez más frecuente en el contexto digital. Esto se debe a que ofrece una gran libertad en el diseño y control de contenido:

WebVTT files provide captions or subtitles for video content, and also text video descriptions, chapters for content navigation, and more generally any form of metadata that is time-aligned with audio or video content (Pfeiffer et al., 2019).

El W3C recomienda la normalización del estilo a través de la estandarización de colores, posición y tamaño del subtítulo, que actualmente se suele incluir dentro de la hoja de estilo en cascada CSS.

Atendiendo a la persona que los elabora, podemos encontrar subtítulos elaborados por profesionales $y$ fansub, es decir, subtítulos elaborados por aficionados (Díaz Cintas y Muñoz Sánchez 2006). Las diferencias entre las características de estos subtítulos son el uso de técnicas y elementos no convencionales en el subtitulado tradicional, como el uso de tipografías diferentes, emoticonos, colores o palabras escritas de manera diferente a la normativa (Shortis 2007).

Atendiendo al formato del subtitulado, encontramos el subtitulado convencional, el subtitulado para sordos, el sobretitulado y el subtitulado adaptado. El subtitulado convencional se caracteriza por describir únicamente los diálogos de un producto audiovisual, es interesante subrayar que el contexto general de visualización de subtitulado se corresponde con las pantallas de espacios públicos, como bares, transporte, tiendas o dispositivos móviles en cines (Costa-Montenegro et al., 2016).

Las características principales del subtitulado para sordos son las siguientes: identificación de los interlocutores a través de colores, guiones o etiquetas; extensión máxima de 37 caracteres por línea a una velocidad aproximada de 15 caracteres por segundo y dispuestos en una o dos líneas; inclusión de información paralingüística y extralingüística; indicar la música y determinar en cursiva la voz en off (UNE 153010:2012).

Esta tipología de subtítulo tiene como principal destinatario a los usuarios con discapacidad auditiva. Teniendo en cuenta la influencia que la lengua de signos tiene en la comunicación de la comunidad sorda, Tercedor et al. (2007b), proponen la adaptación del SpS para facilitar el acceso a la información a las personas sordas signantes:

(a) Utilizar siempre el sinónimo de uso más generalizado, o bien la palabra que se suele vocalizar al signar, por ejemplo "hijos" en lugar de "descendencia".

(b) Seguir un orden cronológico en la secuencia: antes, después.

(c) No omitir los pronombres personales.

(d) Reforzar con adverbios el tiempo verbal ("yo vine tarde ayer"), ya que en LSE se marca el aspecto, pero no la flexión verbal.

(e) Utilizar palabras polisémicas con su significado más conocido. No usar términos simplificados como "banco" para referirse a "banco de arena".

(f) Traducir en palabras lo que la entonación o música expresa claramente.

(g) Abusar de la palabra "ejemplo"; ejemplificar siempre que se pueda.

(h) Evitar sentidos figurados: "no se encuentra bien".

(i) Al usar onomatopeyas, utilizar las de uso generalizado.

(j) Intentar que cada subtítulo tenga sentido completo. 
(k) Sustituir la preposición "de" por estructuras que queden más claras.

(l) "ambos" y "cuyo" son infrecuentes en LSE. Sustituir por "mismo", que también sirve de determinante, ya que en LSE no se utilizan artículos.

(m) Las conjunciones se utilizan poco en LSE, ya que normalmente se marcan con la expresión facial. Al igual que con las preposiciones, sólo las más comunes tienen signo. - "Y”, "también”, "además” sí tienen signo en LSE.

(n) Para las adversativas, mejor utilizar "pero", que es la forma más común y la que ellos mejor entenderían.

(o) Subordinadas adverbiales: es preferible parafrasear para introducir términos con equivalente en LSE ("motivo" para las causales, "resultado" para las consecutivas, "objetivo" para las de finalidad). En otros casos, se recomienda utilizar la preposición más sencilla ("aunque” para concesivas, "si” para condicionales, etc.) (Tercedor et al., 2007b: 89-90).

Respecto del sobretitulado, hemos de indicar que este tipo de subtítulo suele estar asociado especialmente a la ópera (Mateo 2007) y al teatro (Bartoll 2012). Consiste en un tipo de subtítulo que se ubica en la parte superior del escenario. Carrillo (2014: 57) lo define como:

Por sobretitulado entendemos [...] el trasvase interlingüístico de una obra de teatro que se presenta al público de forma simultánea a la representación dramática, por lo general mediante la proyección de unas líneas de texto en una pantalla en un espacio del teatro.

El sobretitulado podemos encontrarlo en las versiones digitales de obras de ópera y teatro.

Seguimos con el subtitulado adaptado. Este tipo de subtítulo se realiza para mejorar accesibilidad a grupos de personas concretos, como personas con discapacidad intelectual, personas mayores o niños. Según Tercedor et al. (2007b), la adaptación entraña habilidades de reducción textual del mensaje oral, además de la adecuación lingüística según las características del producto audiovisual y las necesidades de la audiencia. Estas adaptaciones no solo se limitan a la adecuación lingüística según los usuarios, sino, también, a otros factores como la duración de exposición del subtítulo en pantalla. En los subtítulos adaptados, el diseño centrado en el usuario y la personalización son los elementos clave que determinan la usabilidad del material elaborado (Manchón y Orero 2018).

\subsection{La adaptación textual}

Según Corrigan (2017), la adaptación consiste un proceso que a menudo describe como una o más entidades se reconfiguran o ajustan a través de su relación con uno o más textos u objetos. La adaptación textual puede tener como función principal mejorar la accesibilidad cognitiva, por lo que un texto se puede adaptar para facilitar la comprensión de los receptores del mismo. En este apartado, hemos diferenciado tres tipos de adaptaciones textuales: en primer lugar, encontramos las adaptaciones de textos a lectura fácil, que han de cumplir con unas pautas estandarizadas para mejorar la accesibilidad cognitiva; en segundo lugar, situamos las adaptaciones textuales para públicos específicos, como niños o personas de una cultura específica; y, en tercer lugar, incluimos los sistemas aumentativos y alternativos de comunicación.

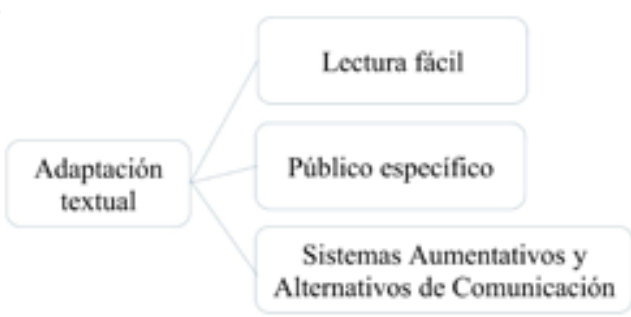

Figura 11. Esquema de la adaptación textual (elaboración propia) 


\subsubsection{La lectura fácil}

La lectura fácil es un sistema que surge ante la necesidad de facilitar la comprensión de la información escrita a finales de los años 60 en Suecia (Johannesson y Qvarsell 1995: 13). Pese a su reciente desarrollo, son numerosas las pautas que se han desarrollado con reconocimiento internacional como: Guidelines for Easy-to-Read Materials de la Federación Internacional de Instituciones y Asociaciones Bibliotecarias o El Camino Más Fácil: Directrices Europeas para Generar Información de Fácil Lectura elaborado por la Liga Internacional de Asociaciones de Personas con Discapacidad Intelectual, actualmente conocida como Inclusion Europe.

La lectura fácil se define según la norma UNE 153101 EX Lectura fácil, pautas y recomendaciones para la elaboración de documentos (Asociación Española de Normalización y Certificación 2018: 7) como:

Método que recoge un conjunto de pautas y recomendaciones relativas a la redacción de textos, al diseño/ maquetación de documentos y a la validación de la comprensibilidad de los mismos, destinado a hacer accesible la información a las personas con dificultades de comprensión lectora. La lectura fácil es una herramienta de accesibilidad cognitiva. Los materiales resultantes de la aplicación del método pueden considerarse productos de apoyo para personas con dificultades de comprensión lectora.

La adaptación de un texto a lectura fácil no solo consiste en realizar una nueva aproximación lingüística y conceptual del contenido, sino que también se abordan elementos del formato y del diseño del texto que pueden facilitar su comprensión (García Muñoz 2012). Las adaptaciones a lectura fácil pueden incluir pictogramas y glosarios. Estos nuevos textos se fundamentan en mejorar la comprensión, pero hemos de conocer previamente que no todas las personas leen de igual manera ya que existe una asimetría de la comprensión asociada a la diversidad de las personas (León 2004). La competencia cognitiva, definida por Calleja Reina (2018: 129) como «la capacidad de una persona para realizar operaciones mentales complejas como relacionar, recordar, interpretar, inferir, etc., y encontrar soluciones a situaciones de acuerdo a un saber específico».

Así pues, entendemos que la competencia cognitiva constituye un elemento fundamental dentro de la comunicación y, para que esta sea efectiva, es necesario tener en cuenta: la funcionalidad de la comunicación, la adecuación de la comunicación y la suficiencia de conocimientos, criterios y habilidades en cuatro dominios: lingüístico, operacional, social y estratégico (Light 1989). Estos criterios, no están relacionados con la extensión temporal o propia del documento, ya que, paradójicamente, los textos en lectura fácil suelen ser más extensos que el texto original y el contenido se encuentra más estructurado desde una perspectiva conceptual.

En el contexto digital, encontramos un mayor número de recursos que facilitan el acceso a la información, como la posibilidad de escuchar el texto en las páginas web y aplicaciones o el uso de subtítulos adaptados en el material audiovisual. De hecho, estudios como el realizado por Alba Rodríguez (2014) que demuestra que adaptar el subtitulado para las personas con discapacidad intelectual mejora la comprensión del mensaje multimedia. El diseño no solo es una parte esencial para los materiales que se encuentran en los entornos, carteles o periódicos, sino también son fundamentales para aquellos que se encuentran en formato digital:

entender el entorno en el que vivimos, comprender todo aquello con lo que nos relacionamos, ya sean personas, objetos o información con la que podamos ser más eficientes respecto a nuestro bienestar y calidad de vida. Todo ello nos posibilita estar mejor informados, nos incrementa una mayor y mejor participación social y nos facilita la inclusión social y cultural (León et al., 2019: 7).

Los avances de la tecnología permiten incorporar una gran variedad de recursos como fotografías, dibujos, pictogramas, vídeos o audios, lo que implica una variedad muy amplia de recursos semióticos utilizados para significar y que confluyen en el mismo evento comunicativo (Manghi 2012: 5). La riqueza de los sistemas de comunicación ha favorecido que se opte por una visión holística del estudio de las habilidades de comunicación:

1. Las habilidades táctiles están relacionadas con la percepción sensorial. La pantalla de la tableta es un medio idóneo para recibir e interpretar estímulos a través del contacto con los dedos.

2. Las habilidades visuales recogen las destrezas y los conocimientos para interpretar y usar las imágenes (fotografías, dibujos, etc.). 
3. Las habilidades auditivas están relacionadas con las aptitudes para interpretar y usar los sonidos y la música.

4. Las habilidades lingüísticas incluyen la capacidad de narrar acontecimientos, de relatar sucesos con precisión y de reconocer las acciones de una historia.

5. Las habilidades cognitivas están centradas en la inteligencia y la memoria.

6. Las habilidades motrices están relacionadas con los movimientos corporales (Comitre Narváez 2018: 210).

Desde la perspectiva del desarrollo de páginas web, Inclusion Europe, a través del proyecto Creando caminos hacia la educación de adultos para personas con discapacidad intelectual, enumera un total de veintiséis elementos que facilitan la accesibilidad cognitiva en este contexto. Estas recomendaciones contemplan diferentes elementos como el diseño de creación de una página web, la mejora en la usabilidad, la facilidad de navegación, el diseño de los elementos de la pantalla y los enlaces.

\subsubsection{Público específico}

Las adaptaciones para un público específico son muy frecuentes en el entorno digital. Existen materiales adaptados para personas mayores, para niños, para personas con diferente lengua materna, para un público experto en áreas específicas, etc. Esta diversidad de tipologías de usuarios limita la determinación de unas características comunes, ya que encontramos textos de una alta especialización y textos más sencillos de comprender. Analizar las posibles adaptaciones textuales digitales para diferentes públicos conllevaría sin duda de una mayor extensión, no obstante, el amplio potencial de esta área de conocimiento será una interesante línea de investigación futura.

Veamos un ejemplo sobre las adaptaciones textuales para los más pequeños. Los niños cada vez tienen más recursos digitales y, según Guernsey (2013) la calidad de un contenido interactivo infantil está directamente relacionada con la adecuación a su edad y específicamente al momento de desarrollo del niño; así, los contenidos digitales deben responder a las capacidades de los usuarios, especialmente los más pequeños, ya que según el estudio de Crescenzi-Lanna y Grané-Oró (2016), el desarrollo de las habilidades cambia radicalmente en los primeros años de vida, por lo que es necesario que los contenidos se puedan adaptar para evitar que la experiencia conlleve afrontar demasiadas barreras. Por ende, los diseños interactivos han de ir de la mano del desarrollo cognitivo y psicomotor, para que el mensaje audiovisual y multimedia favorezca la interacción y no suponga un obstáculo para el niño. En este estudio, se analizan los tipos de interferencias que pueden encontrarse los niños como los textos innecesarios, los mensajes fuera del juego, fondos que distraen, mensajes no eliminables, mensajes con imágenes, figuras distractoras, movimientos distractores, mensajes que interrumpen o los sonidos distractores. Los elementos que, para estos usuarios podrían considerarse como interferencias, posiblemente para otros usuarios podrían ser un complemento o no presentar una interferencia como tal. Además, debemos subrayar que las adaptaciones de materiales para niños suelen recurrir frecuentemente al uso de materiales multimodales por sus beneficios en la adquisición del lenguaje y competencias (Rojas López 2013).

\subsubsection{Los Sistemas Alternativos y Aumentativos de Comunicación}

Delimitar los Sistemas Alternativos y Aumentativos de Comunicación (SAAC) conlleva una dificultad particular, ya que existe una gran variedad de sistemas que podrían encajar en otros apartados y también es necesario considerar que no son sistemas estancos, sino que se pueden adaptar al usuario para facilitar su comunicación. En el caso del sistema bimodal o del alfabeto dactilológico, considerados como sistemas aumentativos de comunicación sin ayuda, hemos decidido recogerlos dentro de la interpretación a sistemas visuales gestuales, mientras que aquellos basados en imágenes, fotografías y pictogramas podrían encajar mejor como adaptaciones textuales que utilizan códigos visuales únicos o complementarios para facilitar la comunicación. La Comunicación Aumentativa y Alternativa se puede definir como:

AAC es un conjunto de herramientas y estrategias que un individuo usa para resolver los desafíos comunicativos cotidianos. La comunicacion puede realizarse de muchas tormas, tales como: habla, mirada compartida, texto, gestos, expresiones faciales, tacto, lengua de signos, símbolos, imágenes, dispositivos que generan el habla, etc. Todos usan múltiples formas de comunicación, basadas en el contexto y nuestro compañero 
de comunicación. La comunicación eficaz se produce cuando otra persona comprende la intención y el significado de un individuo. La forma es menos importante que la comprensión exitosa del mensaje (Burkhart s. f.).

Según Medina Reguera (2018), estos sistemas se caracterizan por lo siguiente:

Estos sistemas sirven a las personas con diversas disfunciones del habla o del lenguaje (o de ambas) para comunicarse con otras personas cara a cara, es decir, se enfocan primordialmente en el plano de la expresión oral. A diferencia de los procesos de subtitulado, audiodescripción, audioguías o lectura fácil, en los que se hacen accesibles los contenidos y productos audiovisuales, la enseñanza o implementación de un SAAC no se refiere a la accesibilidad para la recepción de mensajes sino a la producción, haciendo accesible la propia comunicación de las personas afectadas en su capacidad de hablar.

En este sentido, los SAAC pueden utilizar pictogramas, fotografías e, incluso, signos para expresary comprender mensajes. La diferencia entre un sistema de comunicación aumentativo y un sistema de comunicación alternativo es que el primero se refiere al uso de recursos que complementan la lengua oral para favorecer la comprensión y la expresión de la información, mientras que el segundo se refiere al uso exclusivo de un sistema de comunicación específico como los pictogramas para comunicarse. Hay personas que no utilizan sistemas de comunicación verbales y que emplean estos sistemas de comunicación alternativa en formato físico o digital para comprender los elementos de la casa e incluso para conocer o elegir las actividades que realizan en su día a día. Un ejemplo de aplicación digital a través de pictogramas es el siguiente:

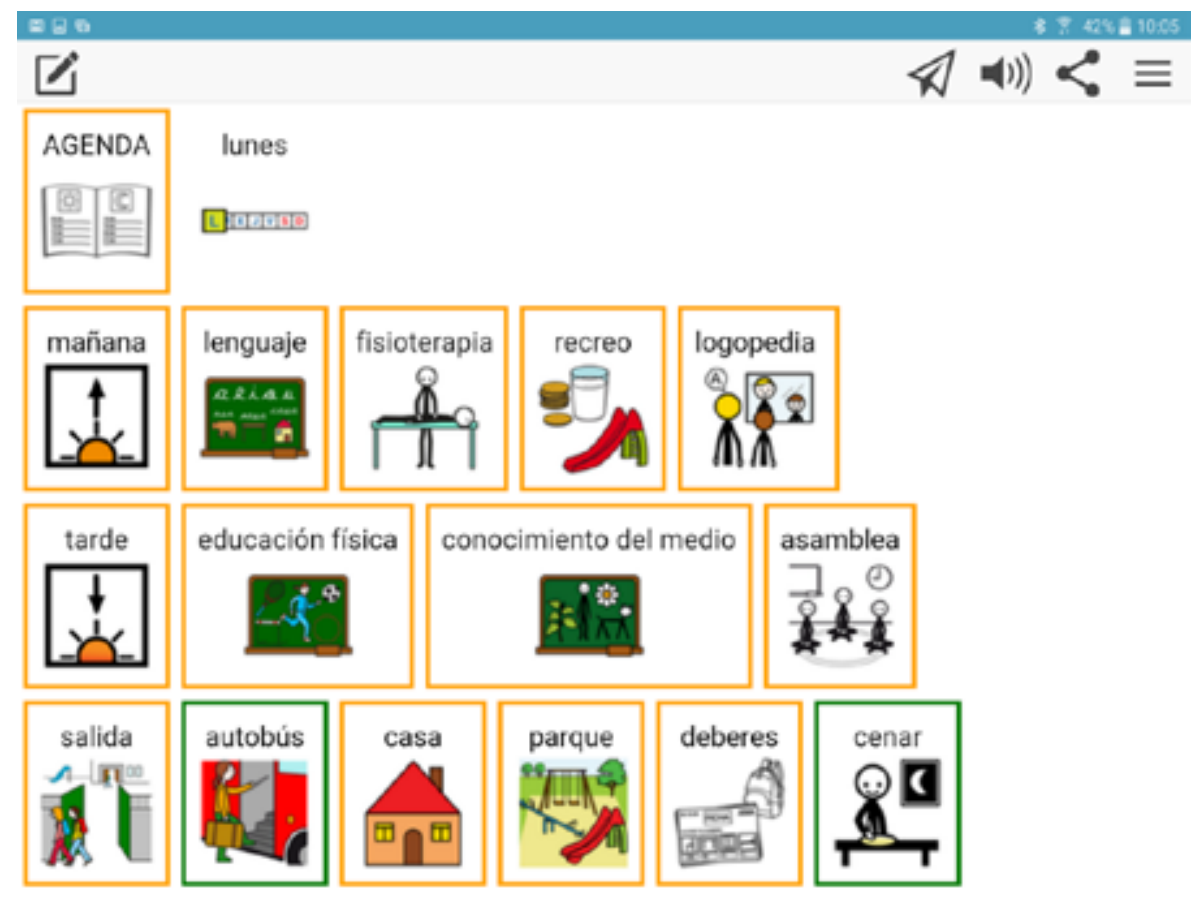

Figura 12. Captura de pantalla de la Aplicación AraWord. Fuente: Confederación de Autismo de España ${ }^{1}$

Esta aplicación de la Confederación de Autismo de España permite utilizar pictogramas del Portal Aragonés de Comunicación Aumentativa y Alternativa (ARASAAC) como recurso comunicativo individual e incluso para realizar construcciones más complejas como la que encontramos en el ejemplo de arriba. En ella podemos ver la organización de un día a través de la agenda, en la que se indican las actividades de la mañana y las actividades de la tarde. Para muchas personas con autismo, tener conocimiento sobre su rutina diaria y las actividades que se van a realizar les proporciona estabilidad. ARASAAC ofrece numerosas herramientas y un extenso catálogo de pictogramas adaptados a diferentes niveles de adquisición del lenguaje que continúa en aumentando desde que se inició en 2007 (ARASAAC 2019). Los sistemas de comunicación con ayuda son aquellos que necesitan de un soporte externo en el que se incluyen: 
a) Sistemas basados en elementos muy representativos, como objetos reales, miniaturas, fotografías o dibujos realistas

b) Sistemas basados en dibujos lineales, como dibujos esquemáticos denominados pictogramas.

c) Sistemas basados en la combinación de símbolos pictográficos, ideográficos y arbitrarios, que permiten la formación de frases complejas.

d) Sistemas basados en estudios con antropoides, que representan un conjunto limitado de conceptos y hoy día no se suelen utilizar.

e) Sistemas basados en la ortografía tradicional, que emplean el alfabeto.

f) Lenguajes codificados con ayuda, que emplean otros elementos para facilitar la comunicación como el tacto a través del braille para personas con discapacidad visual o el sonido a través del sistema morse para personas con dificultades motrices (Correa et al., 2011: 15).

En el contexto digital, cada vez son más los productos y programas de apoyo que se ofrecen para los diferentes usuarios (Medina Reguera 2018). Los productos de apoyo, también conocidos como ayudas técnicas, se definen según Abril Abadín et al. (2013: 5) como:

cualquier producto (incluyendo dispositivos, equipamiento, instrumentos, tecnología y software [SIC]), fabricado especialmente, o disponible en el mercado, para prevenir, compensar, controlar, mitigar o neutralizar deficiencias, limitaciones de la actividad o restricciones en la participación. En definitiva, su objetivo es potenciar la Autonomía Personal y la calidad de vida.

Estos productos pueden ser sistemas específicos de comunicación electrónicos recogidos en la norma UNEEN ISO 9999:2011 de productos de apoyo como el comunicador Go Talk 4.

Otros sistemas basados en programas permiten utilizar teléfonos, tabletas y ordenadores para comunicarse a través de pictogramas o texto. Estos últimos facilitan que los usuarios puedan hablar a través de una voz artificial (Augé y Escoin 2003).

\subsection{Taxonomía}

Teniendo en cuenta las descripciones y delimitaciones que hemos realizado en el apartado anterior, a continuación, proponemos una taxonomía específica de las modalidades de Traducción e Interpretación Accesible en el contexto digital que incluye la descripción verbal, en la que hemos diferenciado la audiodescripción con las submodalidades de audiodescripción general, audiodescripción con apoyo táctil y audioguiado; de los textos alternativos y de las descripciones textuales por las diferencias que presentan tanto en el proceso de creación como en la reproducción para el usuario. A continuación, se encuentra la interpretación a códigos visualesgestuales, en la que se encuentra la interpretación a lengua de signos y lenguaje de señas, el sistema bimodal y los signos internacionales. Continuamos con la transcripción, en la que hemos diferenciado la transcripción textual que se suele utilizar como información complementaria enlazada al objeto en la misma página o en otra diferente y el subtitulado, en el que podemos encontrar las categorías de intralingüístico e interlingüístico, según las lenguas seleccionadas; en directo o pregrabado, según el momento de realización; abierto o cerrado, según la posibilidad de activación; profesional o fansub, según la persona que los elabore; y, atendiendo al formato, están las submodalidades de convencional, subtitulado para sordos, sobretitulado y subtítulos adaptados. Finalmente, encontramos la adaptación textual, en la que hemos diferenciado la lectura fácil, de las adaptaciones para un público específico y los sistemas aumentativos y alternativos de comunicación. 


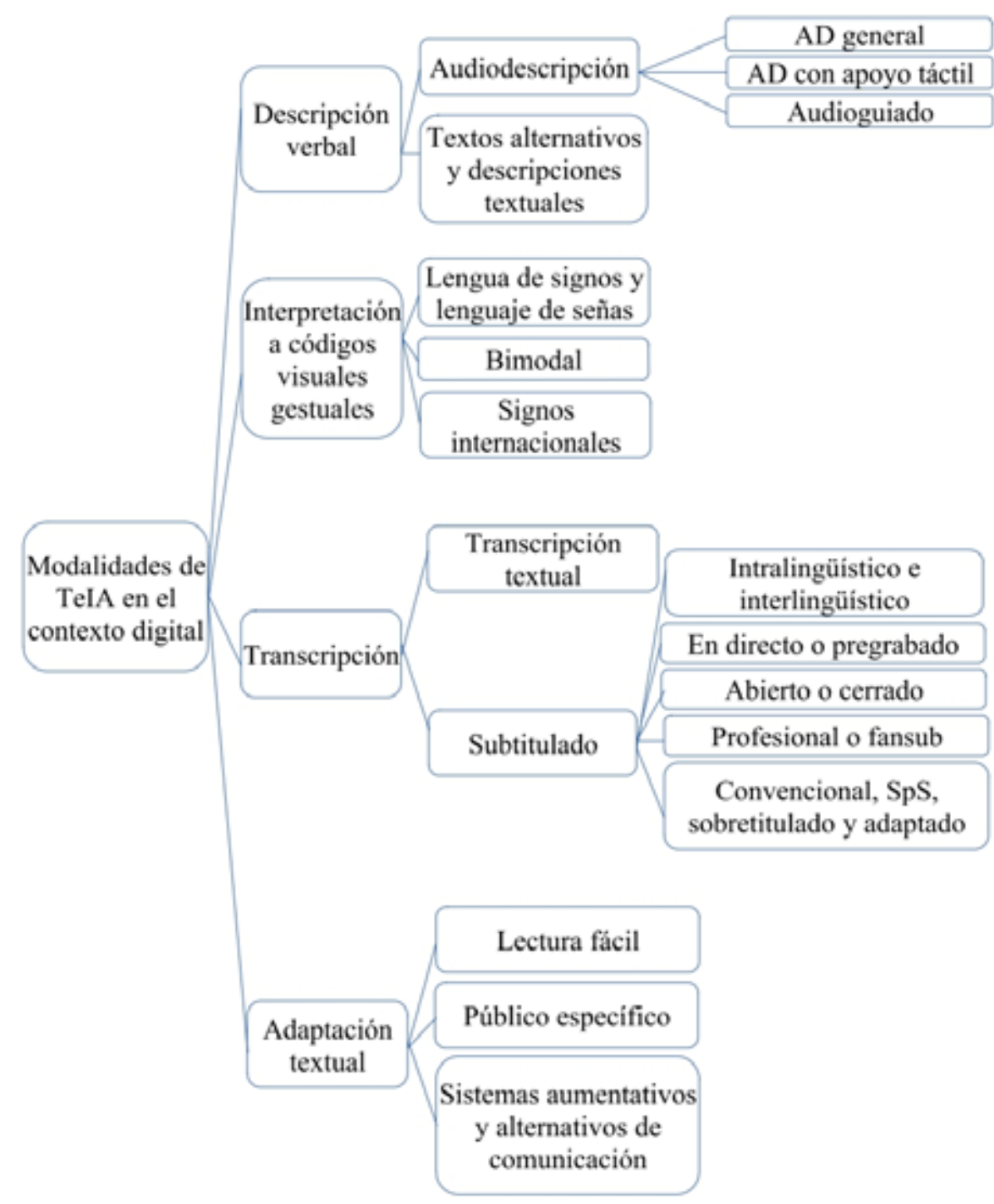

Figura 13. Esquema de las modalidades de Traducción e Interpretación Accesible en el contexto digital

\section{Conclusiones}

En este artículo hemos realizado un recorrido por un contexto de investigación amplio e interdisciplinar, en el que hemos podido realizar un acercamiento de las modalidades de Traducción e Interpretación Accesible en el contexto digital. En este entorno, intervienen los mismos actores que en la comunicación tradicional, no obstante, las características ontológicas de nuestro objeto de estudio lo determinan como un nuevo paradigma que condiciona la autonomía personal y las relaciones sociales. Por ello, hemos realizado este primer acercamiento desde los Estudios de Accesibilidad en el Contexto Digital, en el que las modalidades de Traducción e Interpretación Accesible comparten unas características que las diferencian de otros contextos con el mismo fin: eliminar las barreras comunicativas, sensoriales y cognitivas. Para poder analizarlas en mayor detalle, será objeto de estudio en futuras investigaciones la pormenorización y ampliación de la clasificación preliminar propuesta para las principales modalidades delimitadas: descripción verbal, interpretación a códigos visuales gestuales, transcripción y adaptación textual; ya que su análisis y estudio como elementos del Diseño Universal es clave para profundizar en la implementación de soluciones de accesibilidad efectivas para mejorar la experiencia de los todos los usuarios. 
Bibliografía:

Abril Abadín, D., Delgado Santos, C. I. y Vigara, A. (2010). Comunicación aumentativa y alternativa: guía de referencia ( $3^{\mathrm{a}}$ ed.). CEAPAT.

Aizpurua, A., Harper, S. y Vigo, M. (2016) Exploring the relationship between web accessibility and user experience. International Journal of Human-Computer Studies, 91, 13-23. https://doi.org/10.1016/j. ijhcs.2016.03.008.

Alba Rodríguez, T. (2014). Traducción audiovisual accesible a personas con discapacidad intelectual mediante el uso de subtítulos adaptados. Estudios de traducción 4, 199-209. https://doi.org/10.5209/rev ESTR.2014.v4.45376.

Álvarez de Morales Mercado, C., Limbach, C. y Luque Colmenero, M. (2012). Accesibilidad en la nueva era de las comunicaciones. Profesionales $y$ universidad: un diálogo imprescindible. Ediciones Tragacanto.

Amezcua-Aguilar, T. y Amezcua-Aguilar, P. (2018). Contextos inclusivos: el reconocimiento de la lengua de signos como derecho de las personas con diversidad funcional. Index.comunicación, 8(2), 123148

Arrufat Pérez de Zafra, M. A. (2020). Las metodologías de traducción accesible como herramientas esenciales para la accesibilidad a la información y a la comunicación digital [Tesis doctoral, Universidad de Granada].

Arzelus, H., Álvarez, A., Bernath, C., García, E., Granell,E.y Martínez-Hinarejos, C.D.(2018) The Vicomtech-PRHLT speech transcription systems for the IberSPEECH-RTVE 2018 speech to text transcription challenge, IberSPEECH 2018. Barcelona, España. http:// dx.doi.org/10.21437/IberSPEECH.2018-56

Asociación Española de Normalización y Certificación. (2005). Audiodescripción para personas con discapacidad visual. Requisitos para la audiodescripción y elaboración de audioguías (Norma UNE 153020). https://www.aenor.com/ normas-ylibros/buscador-de-normas une $/ ? \mathrm{c}=\mathrm{N} 0032787$

Asociación Española de Normalización y Certificación. (2012). Productos de apoyo para personas con discapacidad. Clasificación y terminología (Norma UNEEN ISO 9999:2011). https://www.une. org/encuentra-tu-norma/busca-tu-norma/ norma? $\mathrm{c}=\mathrm{N} 0049503$

Asociación Española de Normalización y Certificación (2012). Subtitulado para personas sordas y personas con discapacidad auditiva (Norma UNE 153010). http:// implantecoclear.org/documentos/accesibilid $\mathrm{ad} / \mathrm{UNE}$ 153010_2012.pdf

Asociación Española de Normalización y Certificación. (2018). Lectura Fácil. Pautas y recomendaciones para la elaboración de documentos (Norma UNE 153101 EX). https://www.une.org/encuentra-tu-norma/ busca-tu-norma/norma? $\mathrm{c}=\mathrm{N} 0060036$

Augé, C. y Escoin, J. (2003). Tecnologías de ayuda y sistemas de comunicación aumentativa en personas con discapacidad motora. En F. Alcantud y F. J. Soto (Eds.),
Tecnologias de ayuda en personas con trastornos de comunicación (pp. 139-159). Nau Llibres.

Báez Montero, I. C. y Fernández Soneira, A. M. (2010). Problemas e soluções da tradução/interpretação de textos científicos à Lingua de Sinais Espanhola (LSE) [Ponencia]. Segundo Congresso Brasileiro de Pesquisas em Tradução e Interpretação da Lingua de Sinais. Florianópolis, Brasil.

Barthes, R. (1970). El imperio de los signos. Hill and Wang. https://doi.org/10.5944/ endoxa.40.2017.18332.

Bartoll, E. (2012). La sobretitulació d'obres teatrals. Quaderns. Revista de traducció, 19 , 31-41.

Braun, S. (2007). Audio description from a discourse perspective: A socially relevant framework for research and training, Linguistica Antverpiensia, (6), 357-372.

Burkhart, L. J. (s.f.). ¿Qué es $A A C$ ? International Society for Augmentative and Alternative Communication. https://isaaconline.org/english/what-is-aac/

Cabezas-Gay, N. (2017). Audiodescripción con apoyo táctil en contextos museísticos: evaluación de una nueva modalidad de traducción accesible [Tesis doctoral, Universidad de Granada].

Calleja Reina M. (2018). Sistemas de Comunicación Aumentativa y Alternativa. Ediciones Aljibe.

Carreras, O. (2014). Textos alternativos, imágenes accesibles. Herramientas de ayuda: mapa de decisión y wizard online. Usable y Accesible. https://olgacarreras. blogspot.com/2014/07/textos-alternativosimagenes-accesibles.html

Carrillo Darancet, J. M. (2014). Del original al sobretitulado: la adaptación y la traducción audiovisual en el teatro contemporáneo [Tesis doctoral, Universidad Complutense de Madrid].

Chaume, F. (2004). Cine y traducción. Cátedra.

Comitre Narváez, I. (2018). Multimodalidad en el subtitulado de cuentos interactivos. El caso de Babel con EC+. Disability and Communication. En E. Postigo Pinazo, M. Calleja Reina y E. Gabau Vila (Eds.) Disability and communication. Scientific analysis, total communication, ICT tools and case studies (pp. 191-210). McGraw Hill.

Correa Piñero, A. D., Correa Moreno, T. y Pérez Jorge, D. (2011). Comunicación aumentativa. Una introducción conceptual y práctica. Servicio de Publicaciones de la Universidad de La Laguna.

Corrigan, T. (2017). Defining adaptation. En E. Leitch (Ed.), The Oxford Handbook of Adaptation Studies (pp. 34-47). Oxford University Press. http://doi.org/10.1093/ oxfordhb/9780199331000.013.1

Costa-Montenegro, E., García-Doval, F. M., Juncal-Martínez, J. y BarragánsMartínez, B. (2016). SubTitleMe: Subtitles in cinemas in mobile devices. Universal Access in the Information Society, 15(3), 461-472. https://doi.org/10.1007/s10209015-0420-5.

Crescenzi-Lanna, L. y Grané-Oró, M. (2016) Análisis del diseño interactivo de las mejore apps educativas para niños de cero a ocho años. Revista Comunicar, 46(24), 77-85. http://dx.doi.org/10.3916/C46-2016-08

De los Santos Rodríguez, E. y Lara Burgos, M. P. (2004). Técnicas de interpretación de lengua de signos. Fundación CNSE.

Díaz Cintas, J. y Muñoz Sánchez, P. (2006) Fansubs: Audiovisual translation in an amateur environment. The Journal for Specialised Translation, 6, 37-52.

Díaz Cintas, J. (2007a). Traducción audiovisual y accesibilidad. En C. Jiménez Hurtado (Ed.), Traducción y accesibilidad. Subtitulación para sordos y audiodescripción para ciegos: nuevas modalidades de Traducción Audiovisual (pp. 9-23). Peter Lang.

Díaz Cintas, J. (2007b). Por una preparación de calidad en accesibilidad audiovisual TRANS: Revista de Traductología, (11), $45-$ 59. https://doi.org/10.24310/TRANS.2007. v0i11.3097.

Doan, A., Ramakrishnan, R. y Halevy, A. Y. (2011). Crowdsourcing systems on the World Wide Web. Commun, 54(4), 86-96. https://doi.org/10.1145/1924421.1924442.

Duarte, C., Duarte, C. M. y Carrico, L. (2019). Combining semantic tools for automatic evaluation of alternative texts. W4A'19 Proceedings of the 16th Web For All 2019. Association for Computing Machinery https://doi.org/10.1145/3315002.3317558.

Eco, U. (1975). Tratado de semiótica general Lumen.

Estévez, I. (2009). Sistemas de signos internacional. Contribuciones a las Ciencias Sociales. http://www.eumed.net/rev/ cccss/06/ier.htm

Federico, M. y Furini, M. (2012). Enhancing learning accessibility through fully automatic captioning. W4A'12 Proceedings of the International Cross-Disciplinary Conference on Web Accessibility, ACM, (40), 1-4. https://doi.org/10.1145/2207016.2207053.

Friedman, L. (1976). Phonology of a soundless language: phonological structure of Sign Language [Tesis doctoral, Universidad de California].

Furini, M. (2016). On gamifying the transcription of digital video lectures Entertainment Computing, 14, 23-31. http:// dx.doi.org/10.1016/j.entcom.2015.08.002.

García Muñoz, O. (2012). Lectura fácil métodos de redacción y evaluación. Real Patronato sobre Discapacidad.

Greco, G. M. (2016). On accessibility as a human right, with an application to media accessibility. En A. Matamala y P. Orero (Eds.), Researching audio description. New approaches (pp, 11-33). Palgrave MacMillan. https://doi.org/10.1057/978-1137-56917-2 2 .

Greco, G. M. (2019). Accessibility Studies: Abuses, misuses and the method of poietic design. En C. Stephanidis (Ed.), $\mathrm{HCl}$ International 2019 - Late Breaking Papers. HCII 2019, Lecture Notes in Computer Science (pp. 15-27). Springer. https://doi. org/10.1007/978-3-030-30033-3_2.

Guernsey, L. (2013). Screen time: How electronic media - from baby videos to educational software - affects your young child. Basic Books.

Hassan Montero, Y. (2015). Experiencia de 
usuario: principios y métodos. http://yusef. es/Experiencia_de_Usuario.pdf

Hoareau, C. y Satoh, I. (2009). Modelling and processing information for context-aware computing: A survey. New Generation Computing, 27(3), 177-196. https://doi. org/10.1007/s00354-009-0060-5.

Huitfeldt, C. y Sperberg-McQueen, C. M. (2008). What is transcription? Literary and Linguistic Computing, 23(3), 295-310. https://doi.org/10.1093/1lc/fqn013.

Iwarsson, S. y Stahl, A. (2003). Accessibility, usability and Universal Design - positioning and definition of concepts describing person-environment relationships. Disability and Rehabilitation, 57-66. https://doi org/10.1080/dre.25.2.57.66

Jiménez Hurtado, C. (2007). Traducción y accesibilidad. Subtitulación para sordos $y$ audiodescripción para ciegos: nuevas modalidades de traducción audiovisual. Peter Lang.

Jiménez Hurtado, C. y Soler Gallego, S. (2015). Museums accessibility through translation: A corpus study of pictorial audio description. En J. Díaz Cintas y J. Neves (Eds.), Audiovisual Translation: Taking stock (pp. 277-298). Cambridge Scholars Publishing.

Johannesson, L. y Qvarsell, B. (1995) Den olydiga boken: om lättläst-bokens kommunikativa rum. Tema Kommunikation.

Lapeyre, J. (2018). Aclarar el término "entorno virtual”. Linkedin. https://www.linkedin. com/pulse/aclarar-el-término-entornovirtual-juan-lapeyre/

León, J. A. (2004). Un nuevo enfoque en la competencia lectora basado en diferentes tipos de comprensión. Seminario de primavera 2004, Fundación Santillana, 3950.

León, J. A., Martínez-Huertas, J. A., Jastrzebska, O. y León López, A. (2019). Estudio sobre la comprensión lectora: Una escalera para comprender el mundo. Plena Inclusión.

Liem, B., Zhang, H. y Chen, Y. (2011). An iterative dual pathway structure for speechto-text transcription [Ponencia]. AAA Publications, Workshops at the Twenty-Fifth AAAI Conference on Artificial Intelligence. San Francisco, USA.

Light J. (1989). Toward a definition of communicative competence for individuals using augmentative and alternative communication systems. Augmentative and Alternative Communication, (5), 137-144 https://doi.org/10.1080/0743461891233127 5126.

Luque Colmenero, M. O. y Fernández Díez, M. I. (2015). Ver con los sentidos. Una experiencia de acceso al patrimonio cultural de Jaén con los ojos cerrados. En O. Luque Colmenero, C. Limbach y C. Álvarez de Morales (Eds.), Accesibilidad en la nueva era de las comunicaciones. Profesionales y universidad: un diálogo imprescindible (pp 95-100). Ediciones Tragacanto.

Mace, R. L., Hardie, G. J. y Place, J. P. (1990). Accessible environments: Toward universal design. En W. Preiser, J. Visher y E. White (Eds.), Design interventions: Toward a more human architecture (pp. 155-176). Van Nostrand Reinhold.

Manchón, L. M. y Orero, P. (2018). Usability tests for personalised subtitles. Translation
Spaces, 7(2), 263-284. https://doi. Romero-Fresco, P. (2013). Accessible org/10.1075/ts.18016.man.

Manghi Haquin D. (2012). La perspectiva multimodal sobre la comunicación. Desafíos y aportes para la enseñanza en el aula. Diálogos abiertos, 22(11), 4-15.

Martos Piñas, M. (2019). Audiodescripción: norma y experiencia [Seminario]. Granada, España.

Mateo, M. (2007). Surtitling today: New uses attitudes and developments. Linguistica Antverpiensia, 6, 135-154.

Martínez Martínez, S. (2015). El subtitulado para sordos: estudio de corpus sobre tipología de estrategias de traducción [Tesis doctoral, Universidad de Granada].

Mayoral Asensio, R. (2005). Hacia nuevas investigaciones en la mediación intercultural. Puentes, (6), 3-4.

Medina Reguera (2018). Accesibilidad a la información y a la comunicación. La comunicación aumentativa y alternativa [Materiales inéditos del Experto en Accesibilidad a la Comunicación y a los Contenidos Culturales del Instituto Superior de Lingüística y Traducción (ISTRAD)], $1-42$.

Monfort, M. (marzo de 2006). La comunicación bimodal: desarrollo del lenguaje y comunicación. Revista Virtual. https://www. down21.org/revista-virtual/694-revistavirtual-2006/revista-virtual-marzo-2006 articulo-profesional-marzo-2006/2052 la-comunicacion-bimodal-una-ayudapara-el-desarrollo-del-lenguaje-y-de-lacomunicacion.html

Moreno, A., Pinedo, P. y Rodríguez, A. (2006). Interpretación del sistema de signos internacional. Fundación CNSE.

Nielsen, J. (1993). Usability Engineering Academic Press Professional

Orero, P. (2007). La accesibilidad en los medios: una aproximación multidisciplinar. Trans. Revista de Traductología, (11), 1114. https://doi.org/10.24310/TRANS.2007. v0i11.3094.

rero, P. (2016). From DTV4ALL to HBB4ALL: Accessibility in European broadcasting. En A. Matamala y P. Orero (Eds.), Researching audio description. New approaches (pp. 249-267). Palgrave MacMillan.

Pantula, M. y Kuppusamy, K. S. (2019). AuDIVA: A tool for embedding audio descriptions to enhance video accessibility for persons with visual impairments. Multimedia Tools and Applications, 78(14) 20005-20018. https://doi.org/10.1007/ s11042-019-7363-4.

Pfeiffer, S., Pieters, S., Jägenstedt, P. y Hickson, I. (Eds.) (2019). WebVTT: The Web Video Text Tracks format. W3C. https:// www.w3.org/TR/webvtt1/

Queirós, A., Silva, A., Alvarelhão, J., Pacheco Rocha, N. y Teixeira, A. (2015). Usability, accessibility and ambient-assisted living: A systematic literature review. Universal Access in the Information Society, 14(1), 57-66. https://doi.org/10.1007/s10209-0130328-x.

Rojas López E. (2013). La lectura de textos multimodales en el contexto de proyectos de aprendizaje en la Escuela Primaria [Tesis doctoral, Universidad Autónoma de Barcelona]. filmmaking: Joining the dots between audiovisual translation, accessibility and filmmaking. The Journal of Specialised Translation, (20), 201-223.

Sala, E. \& Alonso, F. (2005). La Accesibilidad Universal en los Municipios: guía para una política integral de promoción y gestión. IMSERSO

Schlesinger, H. S. (1978). The acquisition of bimodal language. En Y. M. Schlesinger \& L. (Eds.). Sign Language of the Deaf: Psychologycal, linguistic and sociological perspective. Academic Press.

Shaqoor Nengroo, A. y Kuppusamy, K. S. (2018). Accessible images (AIMS): A model to build self-describing images for assisting screen reader users. Universal Access in the Information Society, (17), 607-619. https:// doi.org/10.1007/s10209-017-0607-z.

Shortis, T. (2007). Revoicing txt: Spelling, vernacular orthography and 'unregimented writing'. En S. Pasteguillo, M. J. Esteve y L. Geo-Valor (Eds.), The texture of Internet: Netlinguistics in progress (pp. 2-20). Cambridge Scholars Publishing.

Soler Gallego, S. (2012). Traducción y accesibilidad en el museo del siglo XXI. Ediciones Tragacanto.

Soler Gallego, S. y Chica Núñez, A. (2014). Museos para todos: evaluación de una guía audiodescriptiva para personas con discapacidad visual en el museo de ciencias. Revista Española de Discapacidad, 2(2), 145-165. http://dx.doi.org/10.5569/23405104

Soler Gallego, S. y Limbach, C. (2016). Audioguiado en interiores para personas con diversidad funcional visual. En C. Jiménez Hurtado y C. Álvarez de Morales (Eds.) Patrimonio cultural para todos (pp. 33-54). Ediciones Tragacanto.

Stokoe, W. (1960). Sign language structure: An outline of the visual communication systems of the American deaf. Studies in Linguistics. https://doi.org/10.1093/deafed/eni001.

Szarkowska, A., Jankowska, A., Krzysztof, K. y Kowalski, J. (2016a). Open art: Designing accessible content in a multimedia guide app for visitors with and without sensory impairments. En A. Matamala y P. Orero (Eds.), Researching audio description. New approaches (pp. 301-320). Palgrave MacMillan. http://dx.doi.org/10.1057/9781-137-56917-2 16

Szarkowska A., Krejtz I., Pilipczuk O., Dutka, L. y Kruger J. L. (2016b). The effects of text editing and subtitle presentation rate on the comprehension and reading patterns of interlingual and intralingual subtitles among deaf, hard of hearing and hearing viewers. Across Lang Cult, 17(2), 183-204. https:// doi.org/10.1556/084.2016.17.2.3.

Talaván Zanón, N. (2009). Aplicaciones de la traducción audiovisual para mejorar la comprensión oral del inglés [Tesis doctoral, Universidad Nacional de Educación a Distancia].

Tercedor Sánchez, M. y Abadía Molina, F. (2005). The role of images in the translation of technical and scientific texts. Meta, 50(4). https://doi.org/10.7202/019857ar

Tercedor Sánchez, M. y Jiménez Crespo, M. A. (2007). Accesibilidad web, imágenes y traducción técnica: un proyecto piloto. En B. Ruiz Mezcua y F. Utray Delgado (Eds.) 
Accesibilidad a los medios audiovisuales para personas con discapacidad AMADIS, 06 (pp. 129-140). Real Patronato sobre Discapacidad.

Tercedor Sánchez, M., López Rodríguez, C. I. y Prieto Velasco, J. A. (2007a) Accesibilidad web a través de la descripción de imágenes. En B. Ruiz Mezcúa y F. Utray Delgado (Eds.), Accesibilidad a los medios audiovisuales para personas con discapacidad AMADIS' 06 (pp. 73-82). Real Patronato sobre Discapacidad.

Tercedor Sánchez, M., Lara Burgos, P., Torres, S. y Sánchez, J. (2002). Los Herrador Molina, D., Márquez Linares, I. y Márquez Alhambra, L. (2007b). ¿Subtitulamos para todos? Propuesta de criterios para una subtitulación accesible. En Varela, J. (2015). La brecha digital en España. B. Ruiz Mezcúa y F. Utray Delgado (Eds.), Accesibilidad a los medios audiovisuales para personas con discapacidad AMADIS 06 (pp. 83-93). Real Patronato sobre Discapacidad.

Estudio sobre la desigualdad postergada. UGT Secretaría de participación sindical e institucional. http://www.ugt.es/ Publicaciones/BRECHADIGITAL_WEB. pdf

Summary of insights from interviews \& focus groups. En J. Santiago (Ed.), Journal on Technology and Persons with Disabilities (pp. 325-335). California State University Northridge.

multimedia y los sistemas aumentativos de comunicación. Pixel-Bit. Revista de Medios y Educación, 19, 77-92. ázquez Martín, A. (2019). Audiodescripción: norma y experiencia. Manuales Ediciones Tragacanto.

Wald, M. (2011). Crowdsourcing correction of speech recognition captioning errors [Ponencia]. Proceedings of the International Cross-Disciplinary Conference on Web Accessibility, W4A'11. India. https://doi. org/10.1145/1969289.1969318. 